\title{
Characterization of mechanical and electric properties of geopolymers synthesized using four locally available fly ashes
}

\author{
Shixin Zeng, Jialai Wang ${ }^{1}$ \\ Department of Civil, Construction, and Environmental Engineering, The University of Alabama, \\ Tuscaloosa, AL 35487, USA
}

\begin{abstract}
Geopolymer can be synthesized using industrial wastes such as fly ash, making it a promising material to replace Ordinary Portland Cement $(\mathrm{OPC})$ as a green binder for concrete materials. One major barrier to prevent the wide application of geopolymer is that its properties heavily depend on the source materials. Aiming to evaluate the effect of fly ash on the properties of synthesized geopolymers, this study used four carefully selected fly ash to synthesize geopolymers. Comprehensive experimental programs have been carried out to characterize both the mechanical and electrical properties of these geopolymers. Mechanical testing shows that similar chemical composition in the source materials doesn't guarantee similar compressive strengths of the produced geopolymers, and that high content of calcium doesn't always lead to high compressive strength. Electrical characterization shows that both the magnitude of the electrical impedance and the electrical resistance of the geopolymers at early age measured at frequency of $10 \mathrm{KHz}$ increase with the curing time. It has also been found that at the early age, the electric resistance of the geopolymers is mainly determined by the reaction rate. At the late age, this electric resistance is mainly controlled by the chemical composition. Measurements over one year show that the bulk electric resistances or the diameters of the high frequency arcs
\end{abstract}

\footnotetext{
${ }^{1}$ Corresponding author. Tel.: +1 205348 6786; fax: +1 2053480783 .

Email address: jwang@eng.ua.edu (J.Wang)
} 
of all geopolymers increase with age during the one-year testing period, suggesting that the geopolymerization is a very long process.

Keywords: fly ash; geopolymer; mechanical properties; electrical properties; electrical resistance; bulk electrical resistance; geopolymerization

\section{Introduction}

Geopolymers are amorphous three-dimensional alumino-silicate binder materials. They can be synthesized by mixing source material (alumino-silicate reactive materials such as metakaolin, flyashes) and an alkaline activator (strong alkaline solutions such as $\mathrm{NaOH}$ or $\mathrm{KOH}$ ) and then curing at room or elevated temperature. Compared with ordinary Portland cement (OPC), geopolymers possess the following advantages: a) less energy consumption and $\mathrm{CO}_{2}$ emission during manufacture, b) higher strength and much less shrinkage, c) lower permeability (comparable to natural granite), and d) substantially higher resistance to fire and acid attacks. Geopolymers are considered as "green materials" and strong candidates to replace OPC in selected applications leading to more sustainable infrastructure system.

Although geopolymer possesses many advantages compared with OPC, it suffers from a major drawback: its properties largely depend on its source materials such as fly ashes, which vary from source to source in either physical properties, like particle sizes, amorphous proportion, or chemical compositions. Even from the same source, these properties could change significantly too. The difference in the properties of fly ash is resulted from the difference in coals and the way to burn the coal. Therefore, no standard method exists which can predict the properties of geopolymers based on their mix design. In this study, a compressive experimental program has been carried out to synthesize and characterize geopolymers made from Fly ashes from four power plants in and near Alabama. 
Among these four fly ashes, two are low-calcium fly ashes with very similar chemical composition, allowing us to test whether similar chemical composition in fly ash can produce similar properties in the produced geopolymers. Another two are fly ashes with higher calcium content so that the effect of the calcium content, which plays an important role in the properties of the resulted geopolymer, can be examined in this study too.

The effects of these fly ashes on the properties of the produced geopolymers are examined by characterizing the mechanical and electrical properties of the geopolymers. Compressive strength is the major mechanical property measured in this study, as shown in many existing studies. The electrical properties of geopolymers, which have received very little attention in the literature, are also measured. According to existing studies on the electrical properties of OPC [1], the electrical conductivity or resistivity of cement paste is mainly caused by the ion transport through the pore solution in OPC-based concrete, which mainly depends on both pore solution conductivity and porosity. Both the pore solution conductivity and porosity evolve with the hydration of cement, which is a dissolution-precipitation process. At the initial stage of the hydration, the conductivity would increase with the release of the ions from the cement. As the hydration develops, the solid structure would hamper the movement of the charge carriers and the free water in pores used to be connected would be separated, which would decrease the conductivity, as observed in experimental studies [2,3]. Therefore, electric properties measurement is an effective method to study cementitious materials at both the micro- and macroscale. Both the fixed frequency and spectral measurements can be used to study the electrical properties of concrete, as summarized by McCarter et al. [6]. It is reasonable to assume that these methods are also applicable to geopolymers. The electrical properties of geopolymers largely depend on free alkali metal ions. However, very few detailed studies have 
been reported on the electrical properties on geopolymer. Cui et al. [7] investigated the conductivity of geopolymers made with different mix ratios. The measured AC conductivity of the harden geopolymer is $1.5 \times 10^{-4} \mathrm{~S} \mathrm{~m}^{-1}$ at room temperature. Hanjitsuwan et al.[8] measured the electrical conductivity and dielectric constant of fly ash-based geopolymer pastes and found that they are dependent on the frequency range and liquid alkali to ash ratio.

In this study, electric properties of geopolymers made from four different fly ashes were examined using both the fixed frequency and spectral measurements to gain fundamental understanding of the strength development of fly ash based geopolymers.

\section{Materials and Methods}

\subsection{Fly Ashes}

Four locally available fly ashes were chosen to manufacture geopolymer mortar samples. The chemical compositions of these fly ashes are shown in Table 1 . These fly ashes were selected to include both the low-calcium fly ashes (Class F, Gaston, Orlando, and Martin Lake in Table 1) and high-calcium fly ash (Class C, Miller in Table 1). Among three Class F fly ashes, fly ash from Martin Lake has a relatively high calcium content than the other two. In this way, we are able to not only examine whether similar chemical composition in fly ash can produce geopolymers with similar properties, but also estimate the effect of the calcium content on the properties of the geopolymers. In addition, Fly ashes from Gaston and Orlando have nearly the same amount of $\mathrm{Al}_{2} \mathrm{O}_{3}$, as shown in Table 1, allowing us to minimize the effect of the content of $\mathrm{Al}_{2} \mathrm{O}_{3}$ on the produced geopolymers. All fly ashes have $\mathrm{Fe}_{2} \mathrm{O}_{3}$, whose effect on geopolymers are still under study. Limited study [9] suggests that that high iron content in the source fly ash can cause cracking and subsequent strength losses in geopolymers. All three class-F fly ashes have similar content of $\mathrm{Fe}_{2} \mathrm{O}_{3}$. Therefore, the possible influence of $\mathrm{Fe}_{2} \mathrm{O}_{3}$ on geopolymer is not 
considered in this study. The major physical properties of these fly ashes are shown in Table 2.

The particle size distributions are shown in Fig. 1.

Table 1 Chemical composition of chosen fly ashes

\begin{tabular}{lllllllll}
\hline Source & $\mathrm{SiO}_{2}$ & $\mathrm{Al}_{2} \mathrm{O}_{3}$ & $\mathrm{Fe}_{2} \mathrm{O}_{3}$ & $\mathrm{SO}_{3}$ & $\mathrm{CaO}$ & Moisture & LOI & $\mathrm{Na}_{2} \mathrm{O}$ \\
\hline Gaston & $50.38 \%$ & $27.20 \%$ & $9.14 \%$ & $0.30 \%$ & $2.49 \%$ & $0.14 \%$ & $2.95 \%$ & $0.69 \%$ \\
Orlando & $54.48 \%$ & $27.72 \%$ & $8.14 \%$ & $0.11 \%$ & $1.29 \%$ & $0.15 \%$ & $4.11 \%$ & $0.67 \%$ \\
Martin & $54.88 \%$ & $19.31 \%$ & $8.46 \%$ & $0.45 \%$ & $8.03 \%$ & $0.10 \%$ & $0.04 \%$ & $0.62 \%$ \\
Lake & & & & & & & & \\
Miller & $36.23 \%$ & $19.41 \%$ & $6.45 \%$ & $1.84 \%$ & $23.11 \%$ & $0.11 \%$ & $0.61 \%$ & $1.50 \%$ \\
\hline
\end{tabular}

Table 2 Physical properties of chosen fly ashes

\begin{tabular}{lllll}
\hline Source & $\begin{array}{l}\text { Specific } \\
\text { gravity }\end{array}$ & $\begin{array}{l}\text { Fineness }(\% \text { retained on } \\
\# 325 \text { sieve }\end{array}$ & $\begin{array}{l}\text { Mean size } \\
(\mu \mathrm{m})\end{array}$ & $\begin{array}{l}\text { Mid-size } \\
(\mu \mathrm{m})\end{array}$ \\
\hline Gaston & 2.33 & 17.23 & 3.43 & 2.24 \\
Orlando & 2.27 & 14.99 & 3.41 & 2.31 \\
Martin Lake & 2.48 & 21.2 & 3.08 & 2.05 \\
Miller & 2.60 & 17.98 & 2.87 & 2.01 \\
\hline
\end{tabular}

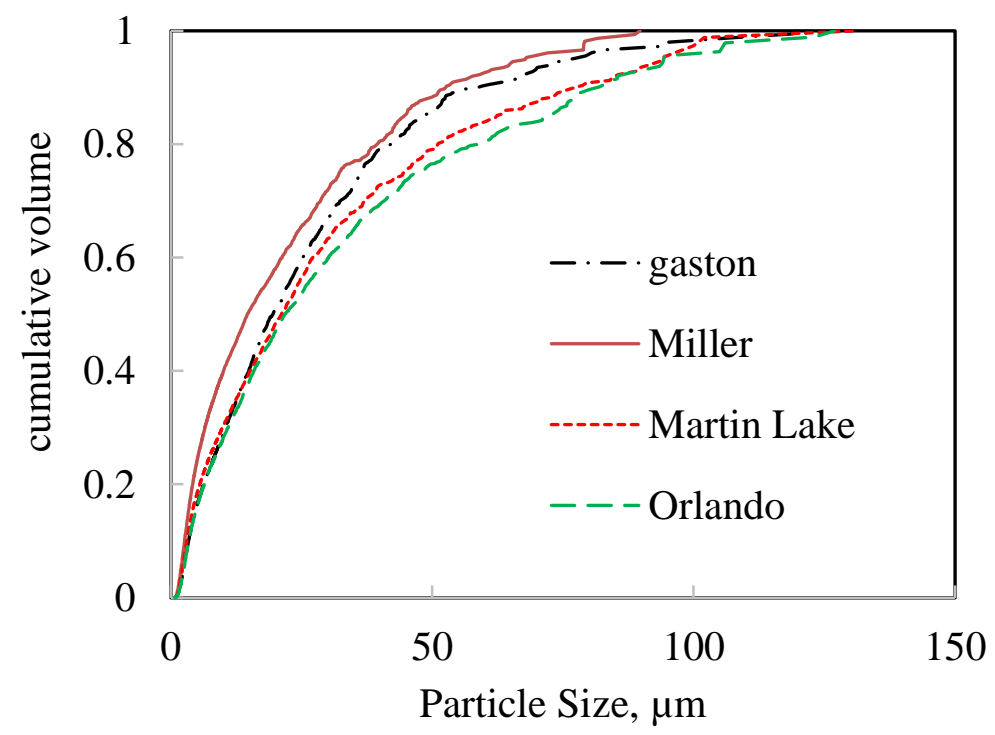

Fig.1 Particle size distribution of fly ashes 
Not all chemical compositions shown in Table 1 participates in the geopolymerization since only the amorphous phases in fly ashes can be dissolved in the alkaline activator, while the crystalline phases become fillers in the resulting geopolymer. To determine the content of the reactive content in fly ash samples, dissolution testing of fly ash was carried out by dissolving the fly ash in $14 \mathrm{M}$ Sodium Hydroxide $(\mathrm{NaOH})$ solution, which was used to manufacture the geopolymer specimens in this study. Five samples were tested for each fly ash following the below testing procedure:

1) Weigh specified amount of fly ashes.

2) Make $\mathrm{NaOH}$ aqueous solution with specified concentration (14M).

3) Mix well the fly ash and $\mathrm{NaOH}$ aqueous solution in a testing bottle.

4) Vibrate the bottle in oven at $75^{\circ} \mathrm{C}$ for 24 hours.

5) Filter the solution for the residue.

6) Weigh the residue and calculate the dissolution degree of the fly ash.

The dissolution degree is defined as the mass ratio in percentage between the materials dissolved in the $\mathrm{NaOH}$ solution and the total mass of the virgin fly ashes. This study uses the dissolution degree as an indicator of the reactivity of the fly ash.

In the initial dissolution testing, about $5 \mathrm{~g}$ of fly ash samples were used to mix with 156 g 14M NaOH solution. This testing shows that the average dissolution degree of four fly ash samples is only $30 \%$, which is much lower than expected. This is because too much fly ash was used in the testing so that $\mathrm{NaOH}$ solution was insufficient to dilute the materials leached out of the fly ash. These materials dissolved from the fly ash then formed precipitants, which couldn't be filtered out by the filter papers used in this testing, leading to much lower measured value of the dissolution degree. By reducing the amount of fly ash 
used in the test, the measured dissolution degree of the fly ash was found to increase accordingly. After the amount of fly ash was reduced to $1.5 \mathrm{~g}$, the measured value of the dissolution degree became stable. Therefore, $1.5 \mathrm{~g}$ fly ash was used in the final dissolution testing.

Scanning electron microscopy (SEM) and Energy-dispersive X-ray spectroscopy (EDX) were used to examine the morphology of the fly ashes before and after dissolution testing. The X-Ray Diffraction (XRD) spectrum was used to determine the change of the crystalline materials within the fly ashes before and after dissolution testing.

\subsection{Geopolymer Mortars}

A mix of $\mathrm{NaOH}$ solution and sodium silicate solution was chosen as the activator of the geopolymer. Sodium silicate solution is lab level from Fisher Scientific containing $29.4 \mathrm{wt} \%$ of $\mathrm{SiO}_{2}, 9.1 \mathrm{wt} \%$ of $\mathrm{Na}_{2} \mathrm{O}$, and $61.5 \mathrm{wt} \%$ of water. Only fine aggregates were used to synthesize geopolymer mortars. Superplasticizer was added as $2.0 \%$ weight of the fly ash to enhance the workability. All geopolymer mortar made in this study contain $60 \mathrm{wt} \%$ of sand. Except for geopolymer made from Martin Lake fly ash, all geopolymers used molar ratio of $\mathrm{SiO}_{2} / \mathrm{Al}_{2} \mathrm{O}_{3}=$ 3.8 and the molar ratio of $\mathrm{Na}_{2} \mathrm{O} / \mathrm{Al}_{2} \mathrm{O}_{3}=0.8$. The concentration of $\mathrm{NaOH}$ was $14 \mathrm{M}$. It is difficult to achieve a $\mathrm{SiO}_{2} / \mathrm{Al}_{2} \mathrm{O}_{3}=3.8$ for Martin Lake fly ash based geopolymer due to low $\mathrm{Al}_{2} \mathrm{O}_{3}$ content in Martin Lake fly ash. The same mix as that of Orlando fly ash was used to produce geopolymer with Martin Lake fly ash since these two fly ashes have similar content of $\mathrm{SiO}_{2}$ and $\mathrm{Fe}_{2} \mathrm{O}_{3}$. This will also allow us to examine the effect of $\mathrm{Al}_{2} \mathrm{O}_{3}$ content on the mechanical properties of the produced geopolymer. The mix designs of these for geopolymer mortars are shown in Table 3. A delay time of two hours was introduced after the geopolymer mortar specimens were cast into the mold and before they were put into the oven for curing because this 
delay time could be beneficial to the strength development [10] of the geopolymers. Then the produced specimens were cured in oven from 4 to 60 hours at $75^{\circ} \mathrm{C}$.

Table 3 Mix design of geopolymer using Gaston fly ash (in mass)

\begin{tabular}{lllc}
\hline Fly ash sources & fly ash (\%) & Sodium silicate (\%) & NaOH solution (\%) \\
\hline Gaston & 24.48 & 8.68 & 6.84 \\
Orlando & 23.2 & 5.9 & 10.53 \\
Martin Lake & 23.2 & 5.9 & 10.53 \\
Miller & 26.39 & 6.42 & 6.98 \\
\hline
\end{tabular}

\subsection{Mechanical Properties Measurement}

Cylindrical samples of geopolymer with size of $50 \mathrm{~mm} \times 100 \mathrm{~mm}$ were manufactured to measure the compressive strength in compliance with ASTM C39-05. Before testing, specimens were capped with sulfate cement so that both surfaces were flat and parallel. The compressive strength was measured for each specimen.

\subsection{Electrical Properties Measurements}

In early study of the electrical properties of concretes, the resistance or its reciprocal, conductance, was measured and related its change to the degree of hydration of the concrete [3, 4]. To this end, the resistance or conductance of the specimen is measured at a fixed frequency of electrical field or a narrow frequency range. The measured electrical resistance is assumed due to the ionic transport in the specimen. An alternating current is usually used to minimize the influence of the electrochemical processes taking place at the electrode/cement interface because the contribution of the electrode/cement interface to the measured resistance is very significant at low frequency and reduces rapidly at high frequency. The major drawback of the resistance/conductance measurement method is that the results are only applicable at certain frequencies of the electrical field. To overcome this problem, electrical impedance spectroscopy 
(EIS) method has been developed, in which the electrical impedance spectrum of the specimen is measured for a large range of frequency [1]. The measured complex impedance spectrum is usually expressed as a Nyquist plot as shown in Fig. 2, in which the $x$-axis is the real part of the impedance and the $y$-axis is the negative of the imaginary part of the impedance. Usually, two arcs exist on a typical complex impedance response of a concrete specimen, as shown Fig. 2. The right arc is the low frequency branch which is related to the effect of the electrode/cement interface. The left arc is the high-frequency branch which reflects the resistance/conductivity of the bulk material, the specimen between the electrodes. Two arcs meet at a point where the imaginary part reaches its minimum. The corresponding real impedance is the bulk resistance of the sample, which is independent of frequency [5].

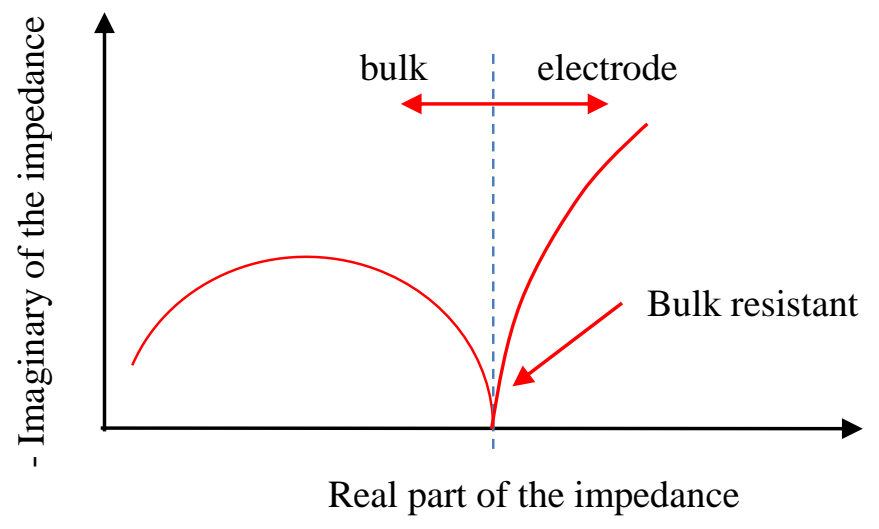

Fig.2 Typical complex impedance response of OPC-based concrete

The electrical properties of the produced geopolymer specimens were studied using both the fixed frequency and the spectral measurements. In the fixed frequency measurement, an AC with frequency of $10 \mathrm{kHz}$ and voltage of $2 \mathrm{~V}$ was applied to the two electrodes embedded in the geopolymer specimen. The current intensity that went through the sample was recorded. The resistance of the specimen was calculated by $R=U / I$, where $U$ is the applied voltage, and $I$ is 
current intensity. In the spectral measurement, a HP 4191A impedance analyzer was used to measure the impedance of the geopolymer specimens.

\section{Results and Discussions}

\subsection{Dissolution of Fly Ashes}

Dissolution testing results are shown in Table 4. It can be seen that Orlando and Gaston fly ashes have similar dissolution degrees, suggesting these two fly ashes may have similar amount of dissolvable material which can participate in geopolymerization. The dissolution degrees of two fly ashes with higher calcium content are much lower, indicating that reactivity of these two fly ashes in geopolymerization can be significantly different from that of two low-calcium fly ashes. Interestingly, the measured dissolution degree decreases with the content of calcium in fly ash. This can be partially attributed to the fast precipitants induced by the calcium in the fly ash during the dissolution testing.

Table 4 Dissolution degree of fly ashes

\begin{tabular}{lllll}
\hline Fly ash & Orlando & Gaston & Martin Lake & Miller \\
\hline Dissolution (\%) & 59.9 & 57.5 & 48.6 & 39.4 \\
\hline
\end{tabular}

The XRD spectra of all four types of fly ashes before and after dissolution testing are shown in Figs. 3 to 6 . These figures show that significant amount of amorphous phases existing in all fly ashes, as indicated by the bumps between $20^{\circ}$ to $40^{\circ}$ on the XRD spectra. After dissolution testing, these bumps were reduced significantly or disappeared, suggesting that amorphous phases in fly ash were dissolved in the alkaline solution in the dissolution testing. It can be seen that the major crystalline materials existing in the fly ash samples are mullite, hematite, quartz, maghemite, and Portlandite as shown in Figs. 3 - 6. 
By comparing the reduction of the bumps, we can find that Gaston fly ash has the highest content of amorphous phases; Orlando fly ash comes next; and the high calcium Miller fly ash appears to contain lowest amorphous materials. This is not in agreement with the dissolution testing results presented in Tables 4, which show that Gaston and Orlando fly ashes have similar dissolution degrees. By examining the XRD spectra of these two fly ashes, we can find that significant amount of zeolite exists in the Gaston fly ash after dissolution testing, as shown in Fig. 3; while very little can be found in Orlando fly ash after dissolution testing even though it has very similar chemical composition as Gaston fly ash, as shown in Fig. 4. Since no zeolite can be identified from the XRD spectrum of the fly ash before the dissolution testing, the zeolite must be produced by the chemical reaction between the alkaline solution and the amorphous phases of the fly ash dissolved in the solution. These zeolites couldn't be dissolved in the alkaline solution and precipitated on the surface of the fly ash, increasing the residual mass of the fly ash. As a result, the calculated dissolution degree in Table 4 is lower than it actually is. This case suggests that dissolution testing is not a reliable method to determine the amorphous phase content in the fly ash.

Compared with low-calcium fly ashes, high calcium Miller fly ash shows a different XRD spectrum after dissolution testing. As shown in Fig. 6, the intensity of most peaks on the XRD spectrum is weaker and considerable amount of amorphous phases still exist after the dissolution testing. This is because that the calcium content in the fly ash can produce fast precipitant (Portlandite as shown in Fig. 6) covering the surface of the fly ash, which not only prevents further dissolving of the fly ash, but also reduces the intensity of the peaks of the crystalline phases. 


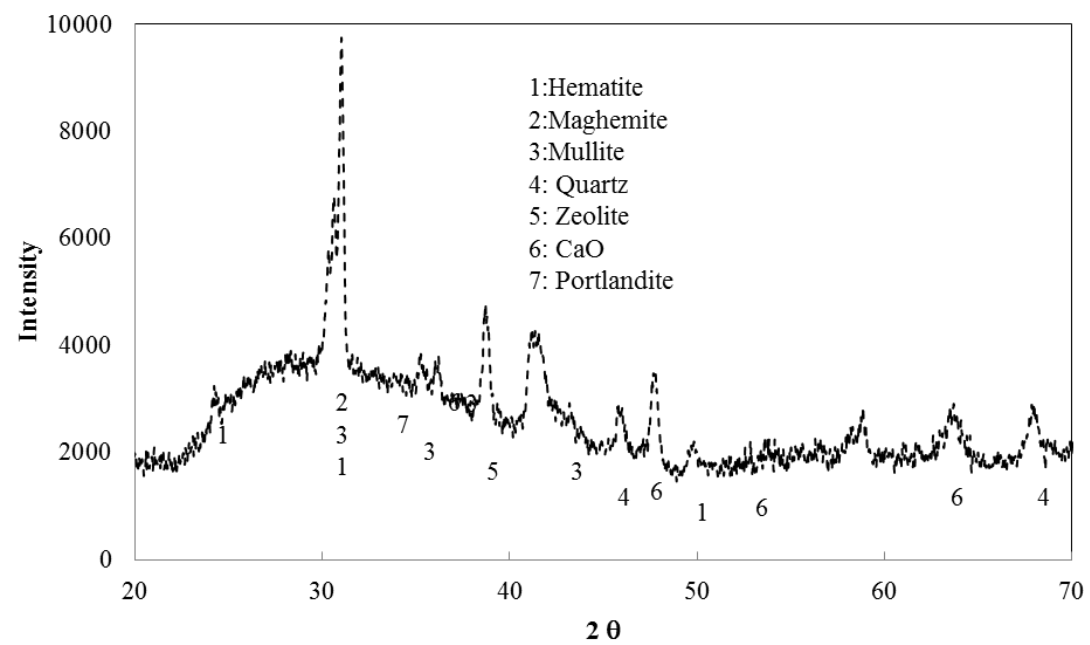

(a)

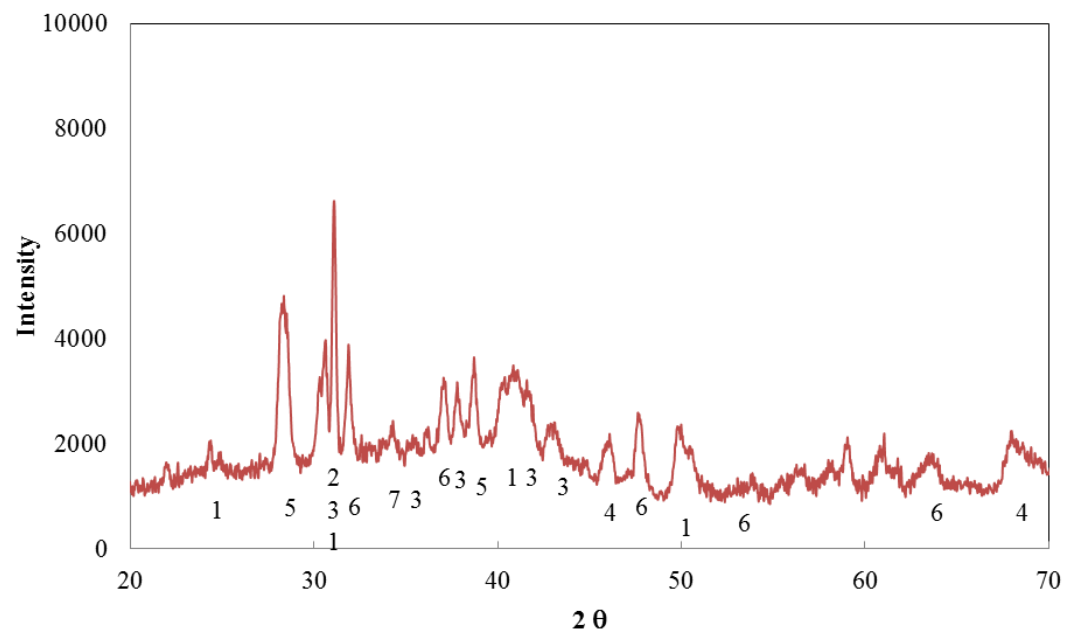

(b)

Fig. 3. XRD of Gaston fly ash: (a) before and, (b) after dissolution testing 


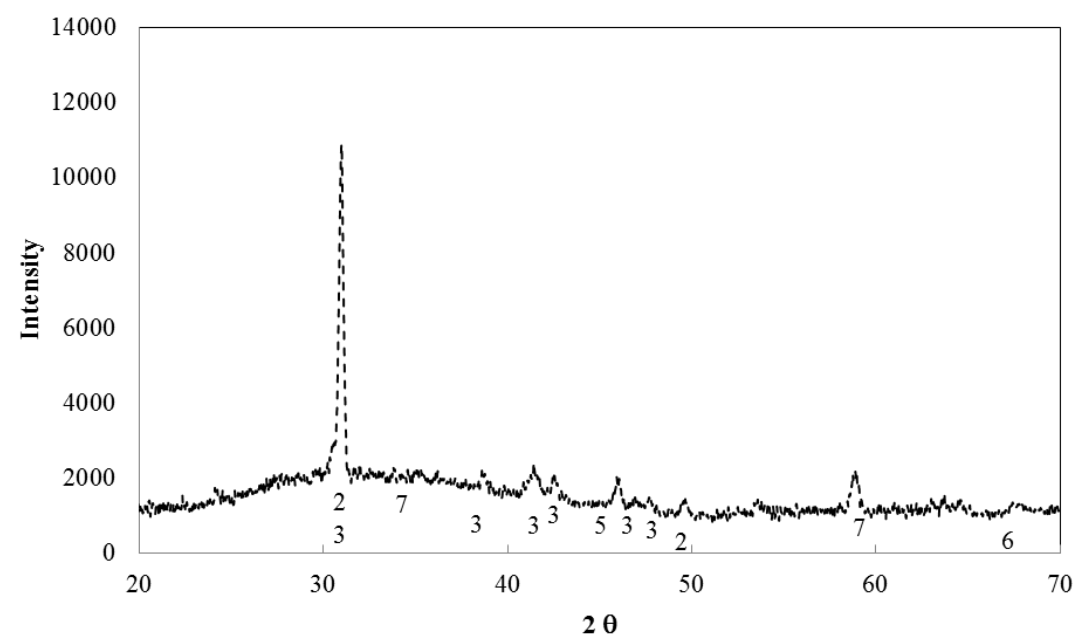

(a)

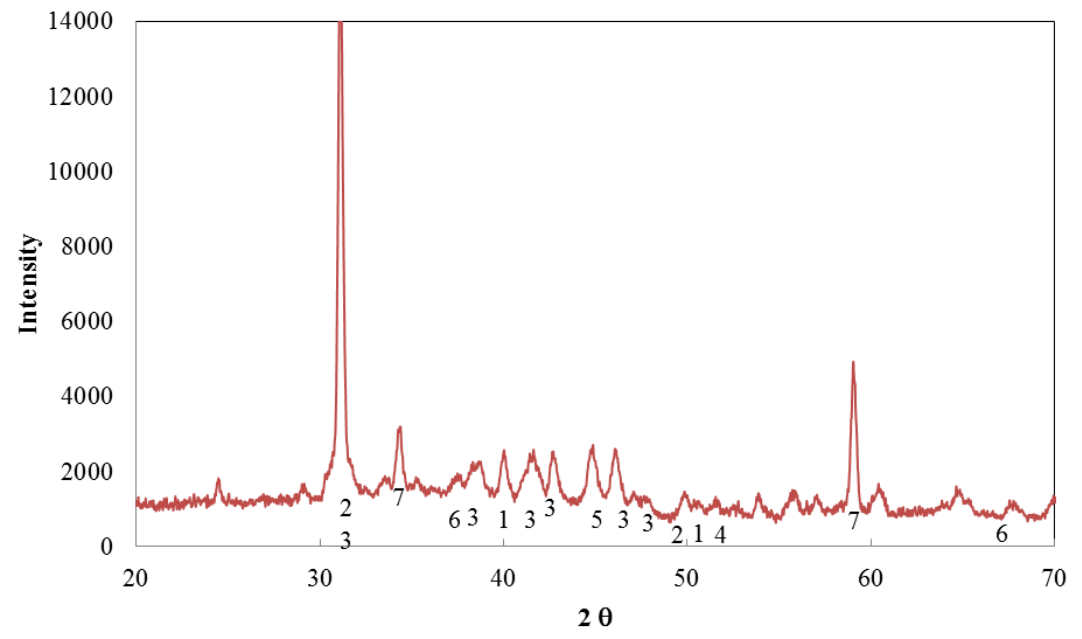

(b)

Fig. 4. XRD of Orlando fly ash: (a) before and, (b) after dissolution testing 


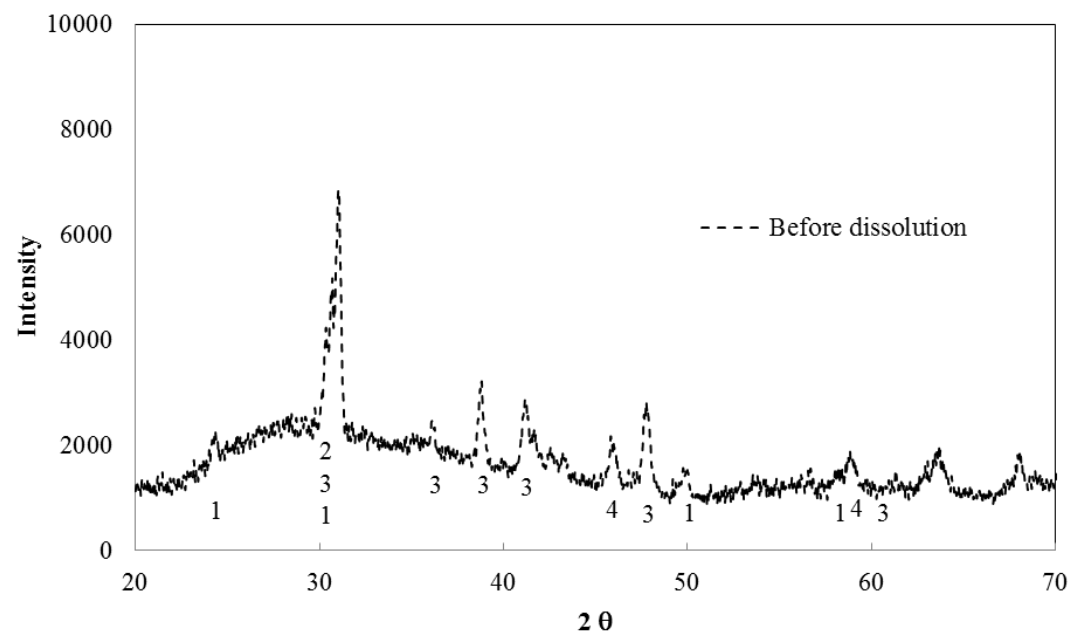

(a)

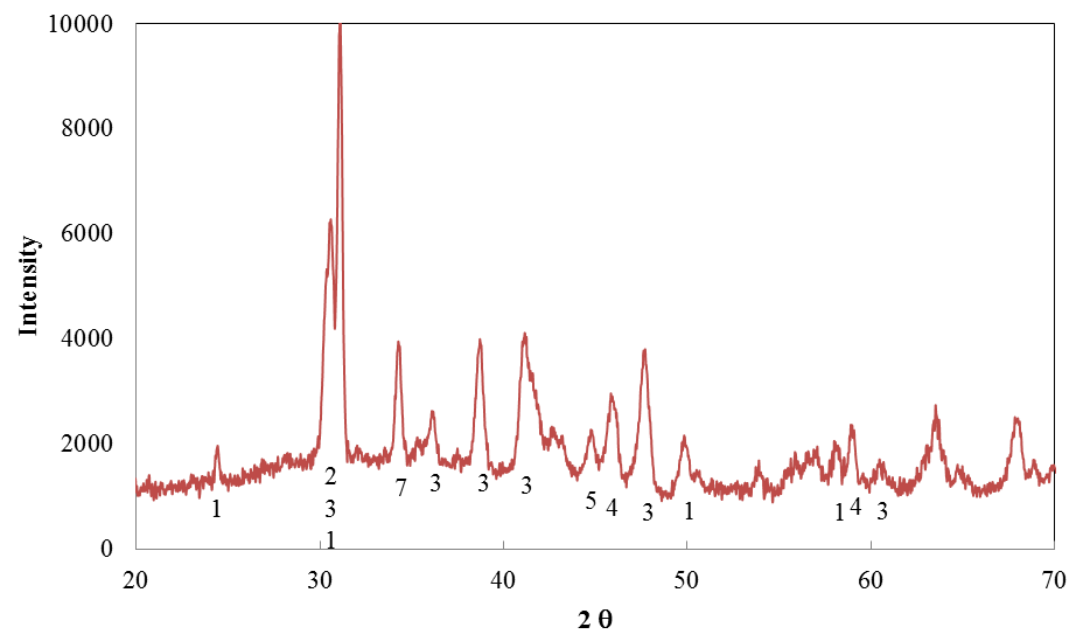

(b)

Fig. 5. XRD of Martin Lake fly ash: (a) before and, (b) after dissolution testing

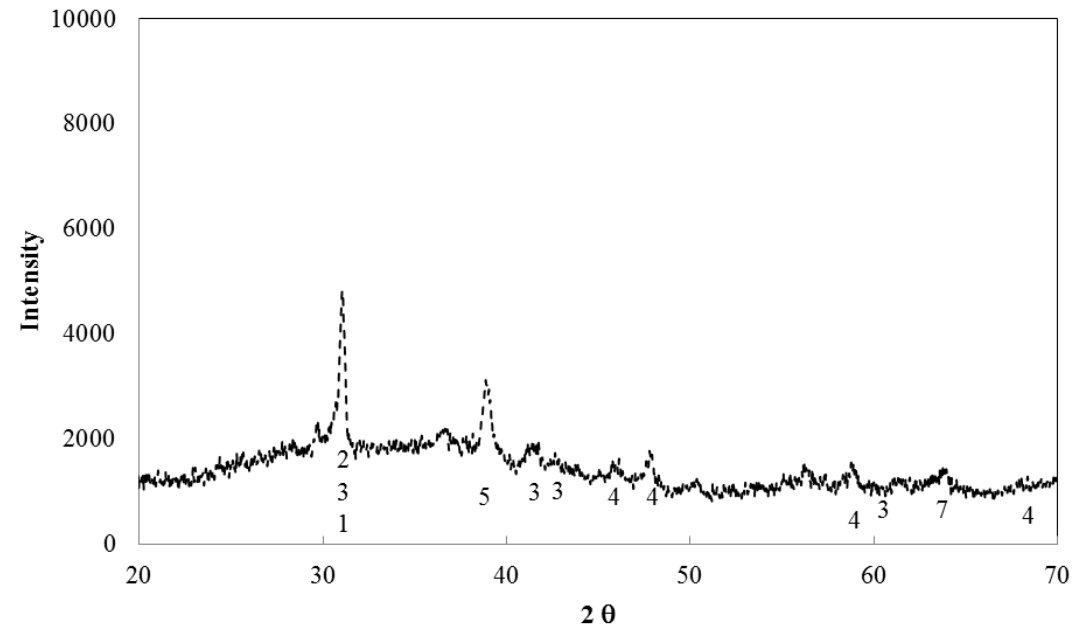


(a)

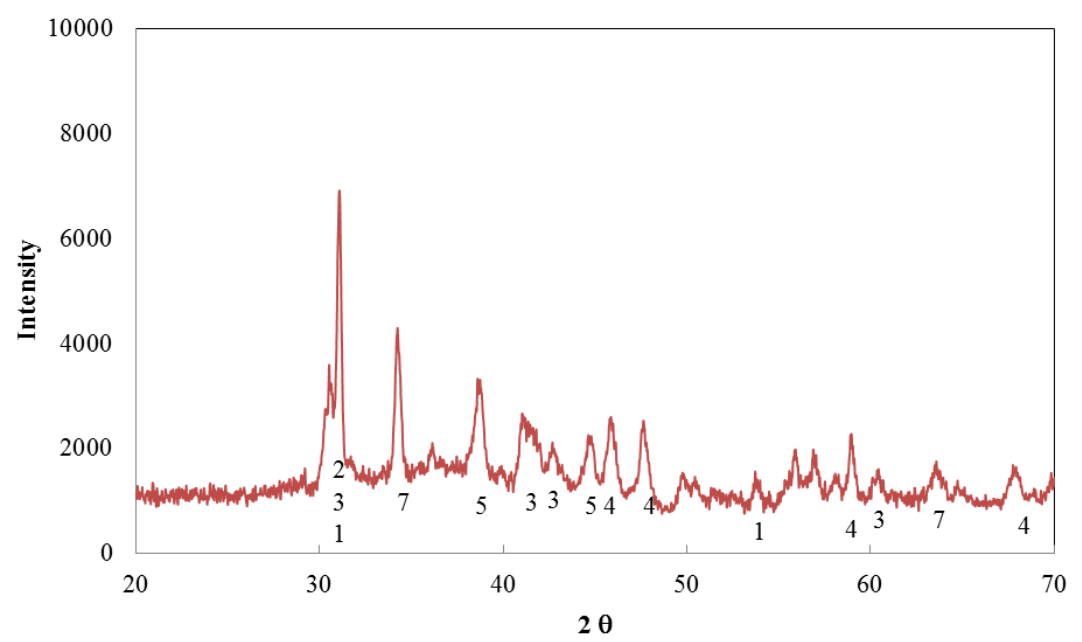

(b)

Fig. 6. XRD of Miller fly ash: (a) before and, (b) after dissolution testing

SEM image of Gaston fly ash after dissolution testing is shown in Fig. 7. It can be seen that crystalline phases were exposed and new precipitant was produced after the amorphous phases dissolved by the alkaline solution. For example, part $A$ indicated in Fig. 7(a) shows that zeolite was produced during the dissolution testing, which agrees with the finding obtained by the XRD analysis as shown in Fig. 3. The Part $B$ indicated in Fig. 7(b) is the Mullite, which exists in all fly ashes as shown in Figs. 2-5. Another mineral existing in all fly ash is hematite, which is identified and labeled as $C$ in Fig. 7(c).

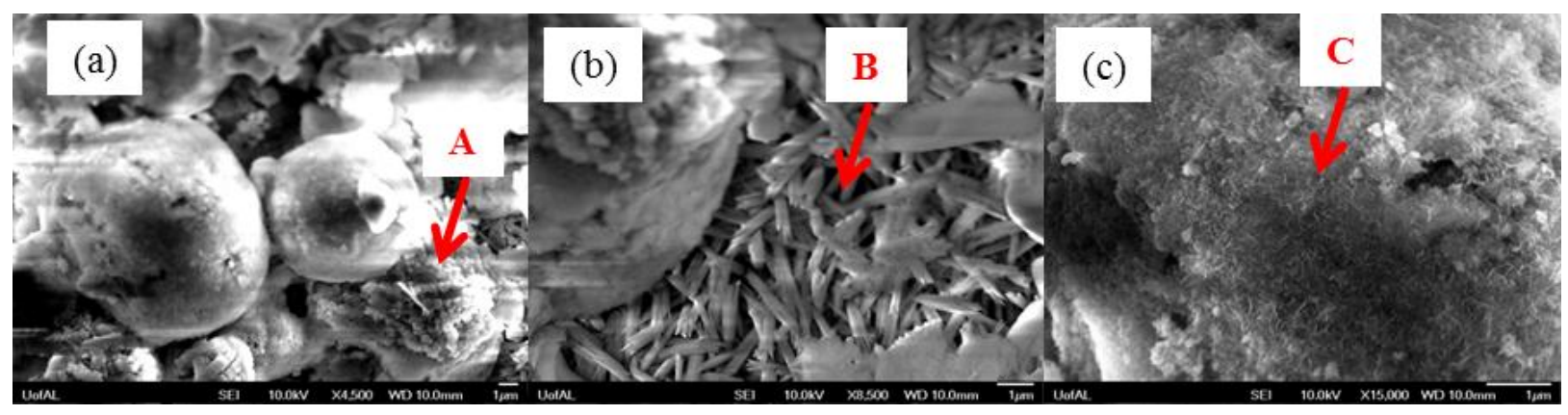

Fig. 7 SEM images of Gaston fly ash after dissolution testing 
Figure 8 shows the SEM images of the residue of Orlando fly ash after dissolution testing. Similar to Gaston fly ash, most amorphous phases on the surface of the fly ash particles were dissolved, and the crystalline phases were therefore exposed. The majority of these crystalline phases are Mullite, as also shown by XRD analysis (Figs.3 - 6). These residue minerals covers the surface of the fly ash particle, which may prevent further dissolving of amorphous materials from this fly ash. Some precipitant can be identified in Fig. 8(a), which is the Portlandite as indicated in XRD spectrum (Fig. 4) induced by the reaction of calcium content in the fly ash with the alkaline solution.

The SEM images of the Martin Lake fly ash after dissolution testing is shown in Fig. 9. Similar to Gaston and Orlando fly ashes, Mullite is the major mineral residue of this fly ash after dissolution testing, as shown in Fig. 9(c). However, much more precipitants (Portlandite) can be seen (Figs. 9(a) and 9(b)), which is caused by the relatively high content of $\mathrm{CaO}(8.03 \%)$ in this fly ash. These precipitants may be also responsible for the low dissolution degree of this fly ash (Table 4).

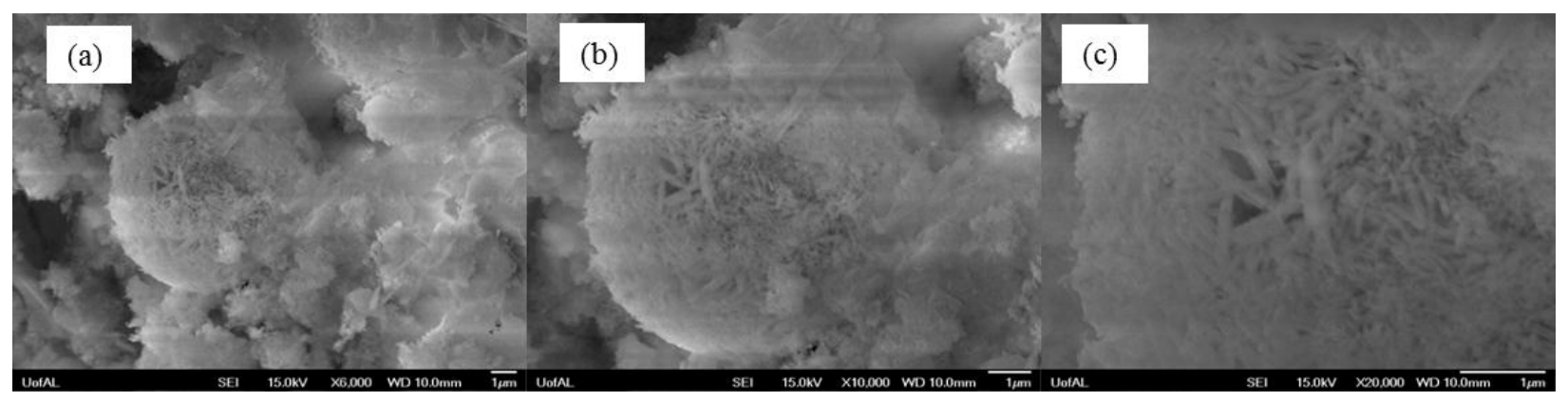

Fig. 8 SEM images of Orlando fly ash after dissolution testing 


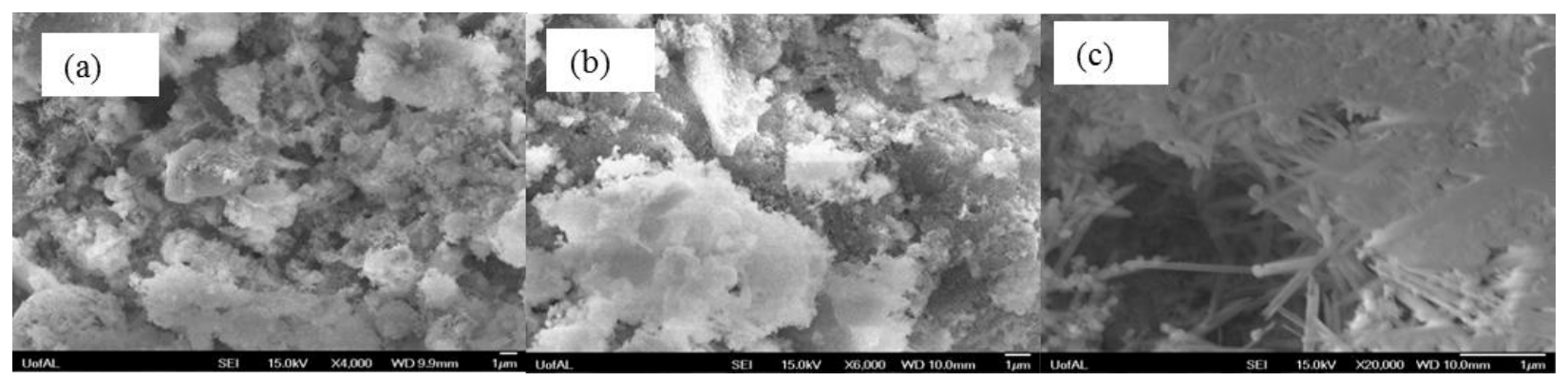

Fig. 9 SEM images of Martin Lake fly ash after dissolution testing

The SEM images of the high calcium fly ash from Miller are shown in Fig. 10.

Significant amount of precipitant (Portlandite) was produced (Fig. 10(a)) due to the high calcium content. For this reason, the dissolution degree measured for this fly ash is much lower than low-calcium fly ashes. Figure 10(c) also shows that the major mineral residue of this fly ash is Mullite, same as other fly ashes.

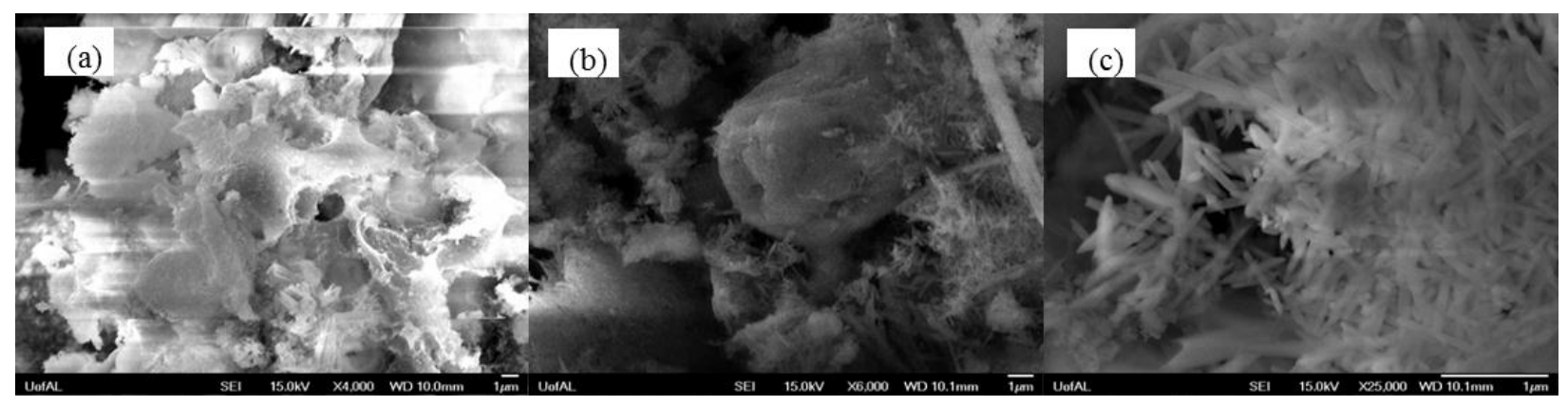

Fig. 10 SEM images of Miller fly ash after dissolution testing

\subsection{Mechanical Properties of Geopolymers}

The compressive strengths of four geopolymer mortars cured at $75^{\circ} \mathrm{C}$ with different curing times are shown in Fig. 11. It can be seen that the compressive strengths of these specimens increase with curing time and reach their maximum about 22 hours curing, suggesting that most geopolymerization has been completed within this period. Figure 11 also shows that excessive curing can even slightly reduce the compressive strength of the geopolymers. 


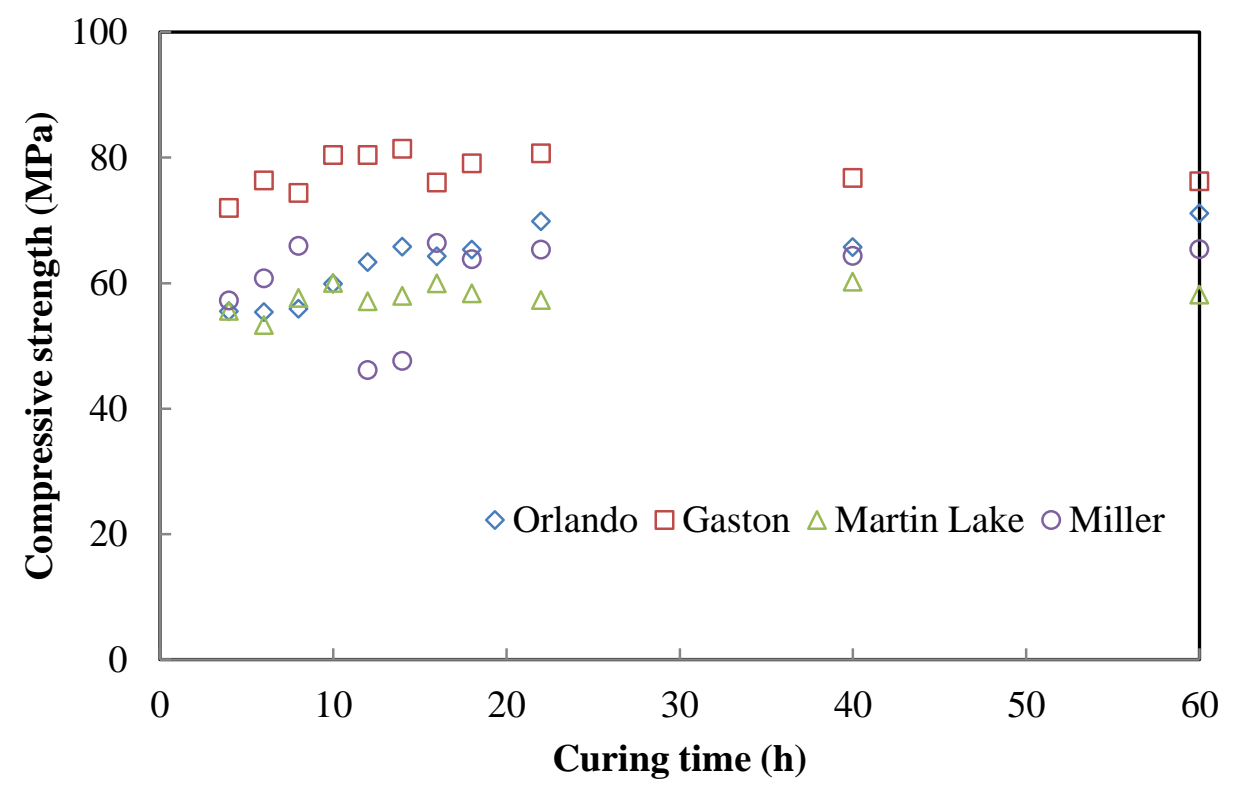

Fig. 11 Compressive strengths of geopolymer specimens varying with curing time

Figure 11 shows that geopolymer using Gaston fly ash has the highest compressive strength. The geopolymer based on Orlando fly ash is lower, even though its chemical composition and dissolution degree are very close to that of Gaston fly ash. The major reason for this difference in strength is that the content of amorphous phases in Gaston fly ash is higher than that in Orlando fly ash, as indicated by the XRD spectra of these two fly ashes (Figs. 3 and 4). Because both of the measured dissolution degrees and the XRD spectra of fly ashes from Martin Lake and Miller suggest that the amorphous material content of these two fly ashes are lower, the compressive strengths of geopolymer made with these two fly ashes are lower too. This observation is different from Van Jaarsveld et al.'s study [14], which shows that higher calcium content fly ash produces greater compressive strength. The result of this study suggests that calcium content is not the only factor affecting the strength of the geopolymers. Geopolymer based on fly ash with higher 
calcium content could have lower strength if they have less reactive materials participating geopolymerization process.

Figure 12 (a) shows the microstructure of the geopolymer using the Gaston fly ash. A few unreacted fly ash residues can be clearly identified from this figure. Element mapping shows that no or little Na element can be found on the surface of these fly ash residues, suggesting that the minerals covering the surface of the unreacted fly ash particles are nonreactive mineral in the fly ash, not geopolymer gel. Except the fly ash residues, other area shown in Fig. 12(a) is rich in $\mathrm{Al}, \mathrm{Si}$, and $\mathrm{Na}$, as shown in Figs. 12(b), (c), and (f), indicating that geopolymer gel has been produced. No or little Ca can be identified from this sample as shown in Fig. 12(d). This is anticipated since Gaston fly ash has very low Ca content. A shrinkage crack is also present which is very common for most geopolymer cured at elevated temperature.

Figure 13 shows the microstructure and element mapping of the geopolymer based on Orlando fly ash. Similar to the previous case, some unreacted fly ash can be found. Element mapping shows that geopolymer gel is the major product in the observed area. Some needlelike crystals can be seen in this image. Element mapping shows that these crystals are rich in $\mathrm{Na}$ and $\mathrm{O}$ and contain no or little $\mathrm{Ca}, \mathrm{Si}$, and $\mathrm{Al}$. Therefore, most likely, these crystals are unreacted alkaline $\mathrm{NaOH}$. 


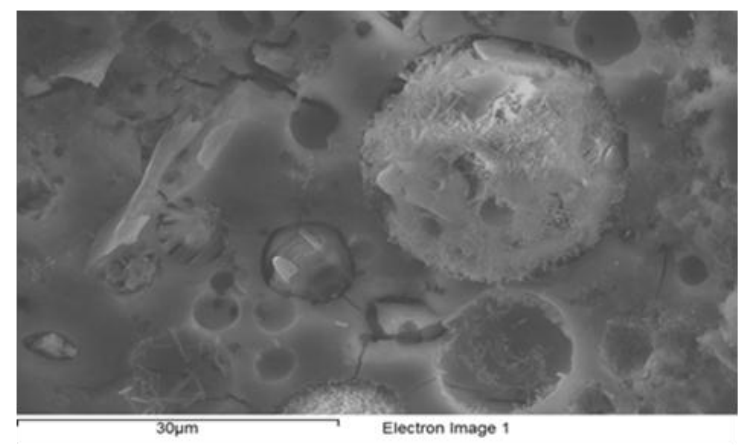

(a)

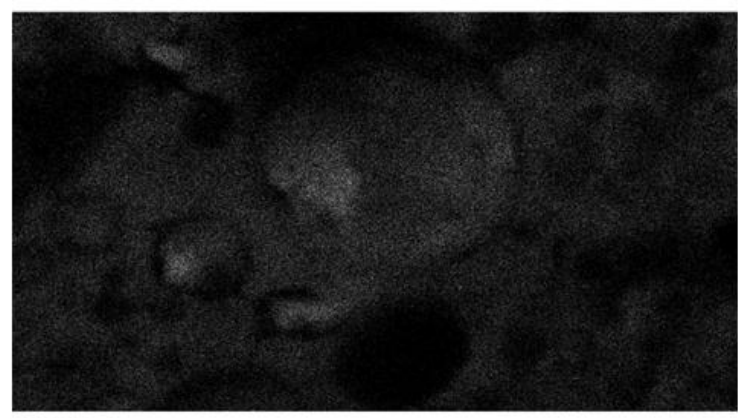

Si Ka1

(c)

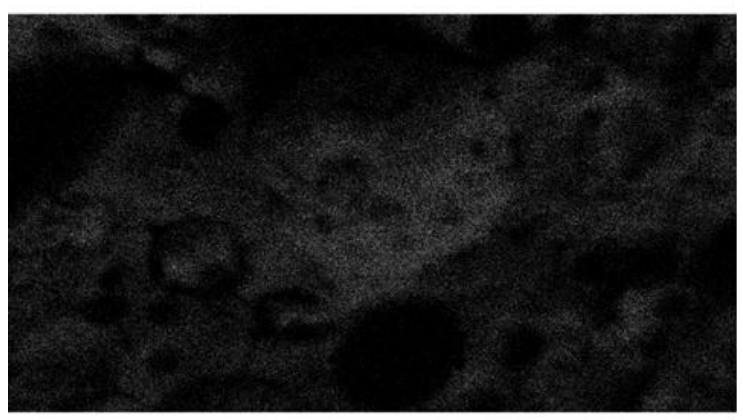

O Ka1

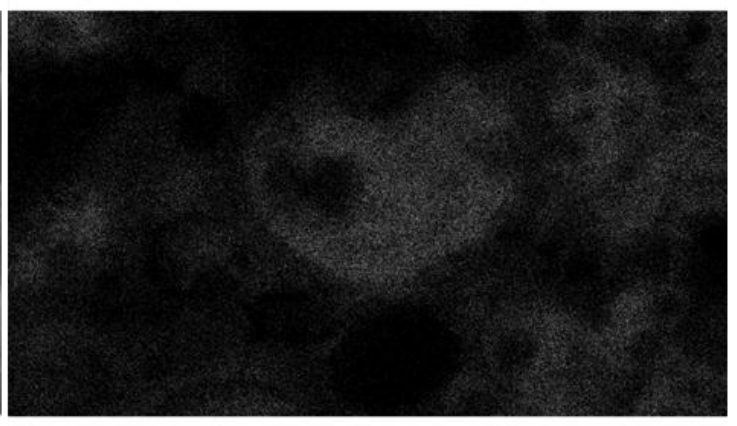

Al Ka1

(b)

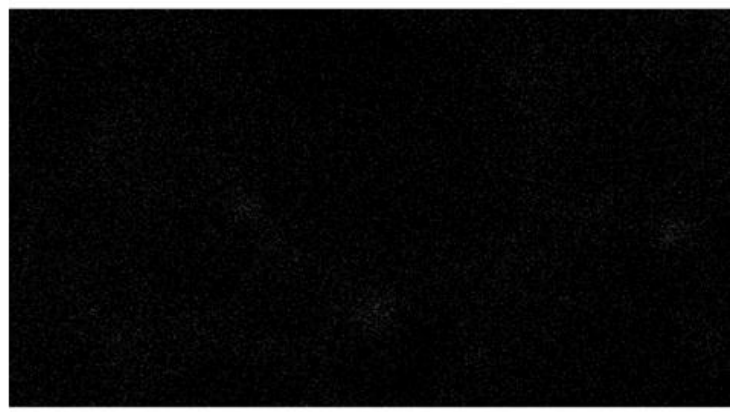

Ca Ka1

(d)

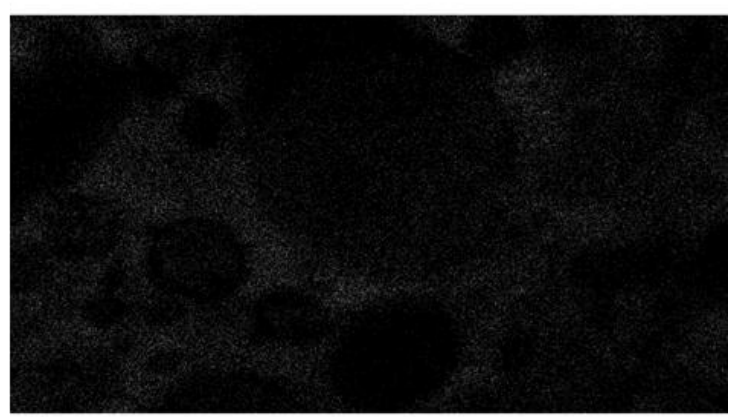

Na Ka1_2

(f)

Fig. 12 SEM image and element mapping of geopolymer using Gaston fly ash: (a) SEM image; (b) Al mapping; (c) Si Mapping; (d) Calcium mapping; (e) O mapping; (f) $\mathrm{Na}$ mapping. 


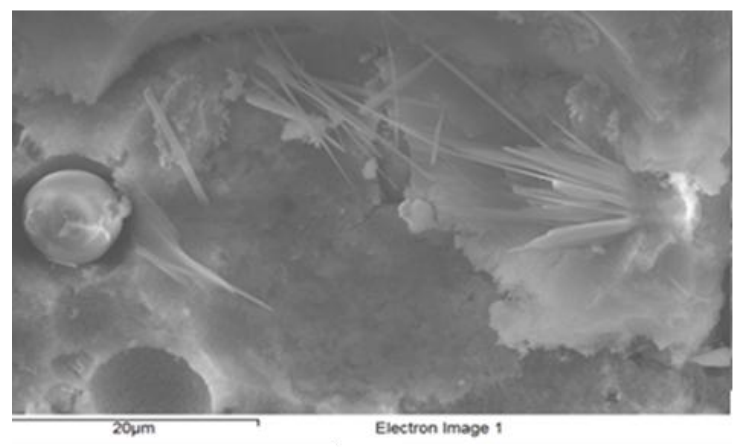

(a)

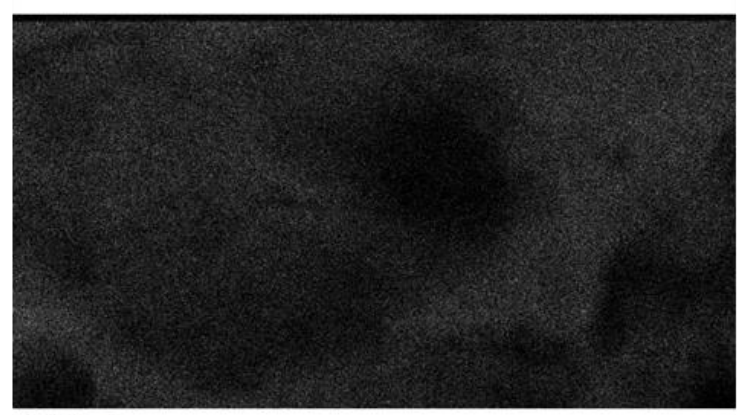

Si Ka1

(c)

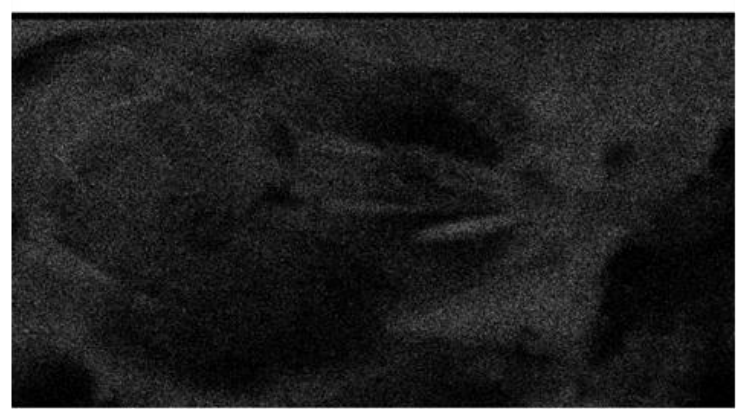

O Ka1

(e)

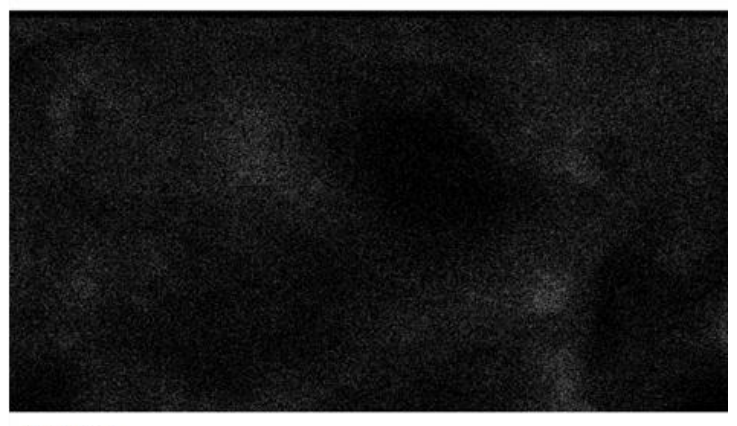

(b)

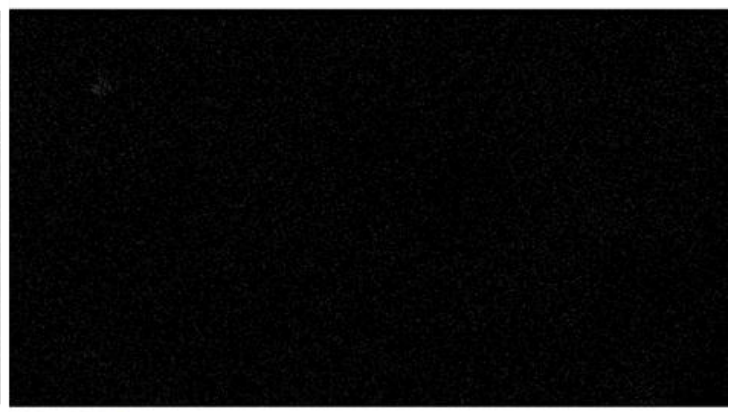

(d)

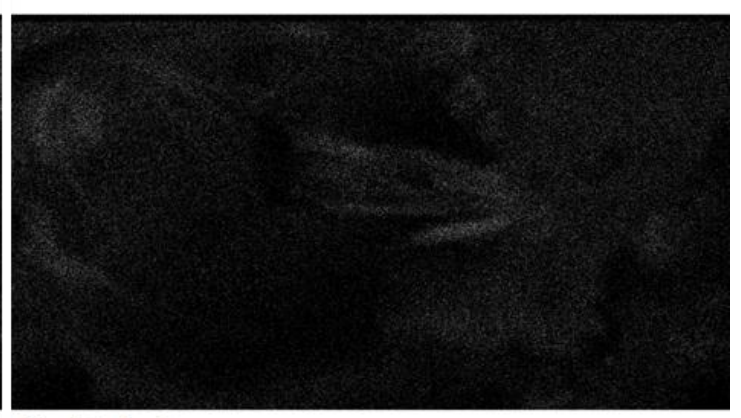

Na Ka1_2

(f)

Fig. 13 SEM image and element mapping of geopolymer using Orlando fly ash: (a) SEM image; (b) Al mapping; (c) Si mapping; (d) Calcium mapping; (e) O mapping; (f) Na mapping.

Figure 14 shows the microstructure and element mapping of the geopolymer samples based on Martin Lake fly ash. Some unreacted fly ash particles can be found in this geopolymer sample. Unlike in the previous two cases in which part of the fly ash particles have been dissolved, the fly ash particles present in this sample have smooth surfaces, indicating little materials dissolved from the fly ash and participated in the geopolymerization. This can be 
confirmed by the element mapping. As shown in Figs. 14(d), and (f), these particles are rich in Ca but contain no or little Na. This observation agrees very well with the dissolution testing result. It also explains why this geopolymer is weaker. Figure 14(d) shows that most calcium was not leached out of the fly ash and still locked within the fly ash particles. Therefore, no binder other than geopolymer can be found in this sample even though the fly ash contains $8.03 \%$ of $\mathrm{CaO}$.

Figure 15 shows the microstructure and element mapping of the geopolymer sample based on high calcium fly ash from Miller. More shrinkage cracks can be found in this sample which could be caused by the high calcium content. A calcium-rich area has been identified on Fig. 15(a) and (d). In this area, no or little $\mathrm{Na}$ or $\mathrm{Al}$ was found while $\mathrm{Si}$ is abundant. Therefore, very likely, calcium silicate hydrate (C-S-H) is produced in this area due to the high calcium content in the fly ash, which can reinforce the geopolymer gel, and make it stronger than the geopolymer based on Martin Lake fly ash. 


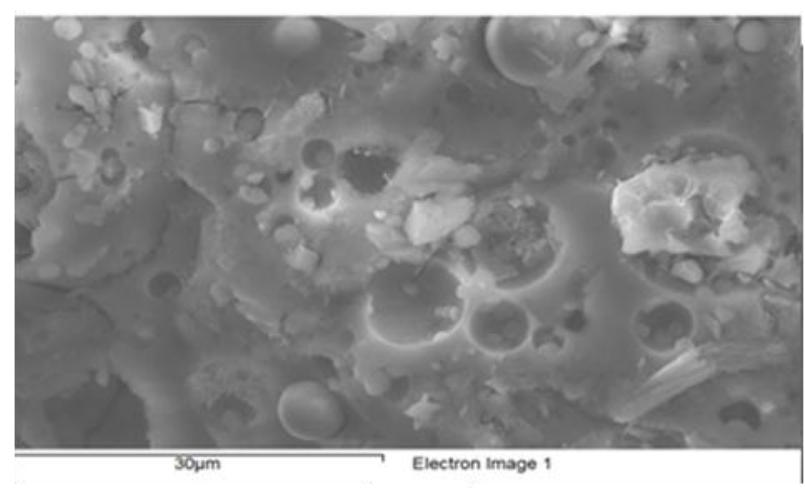

(a)

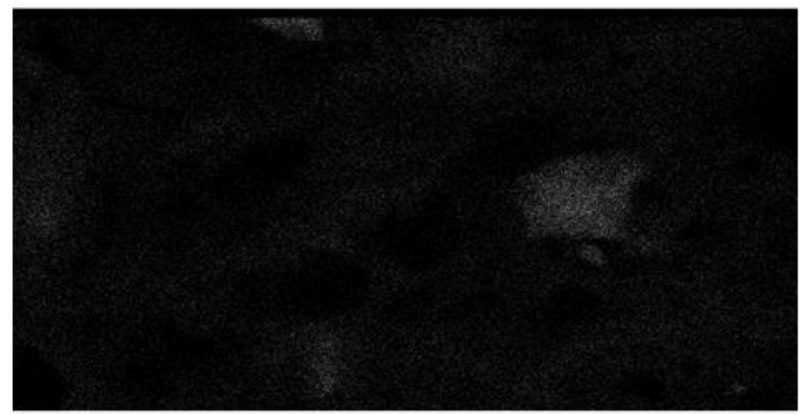

Si Ka1

(c)

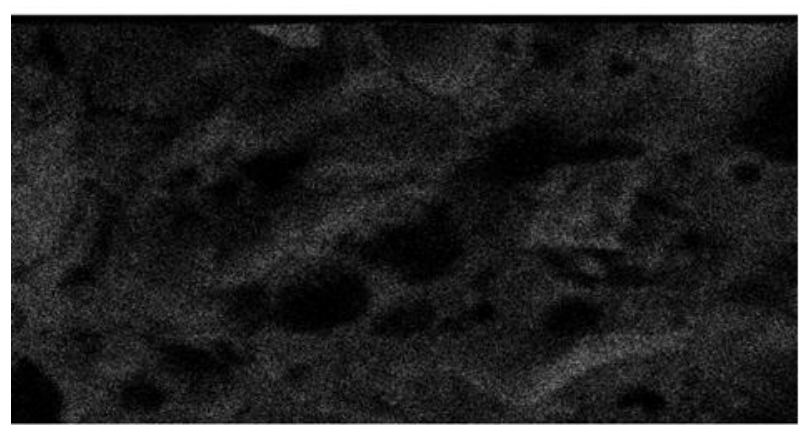

O Ka1

(e)

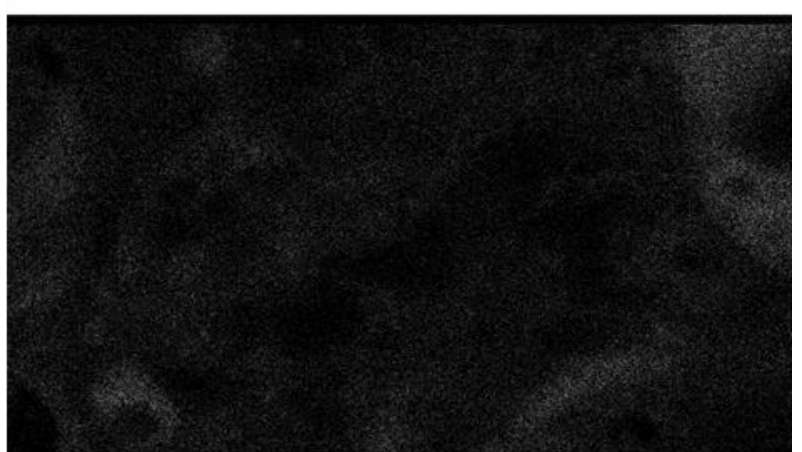

Al Ka1

(b)

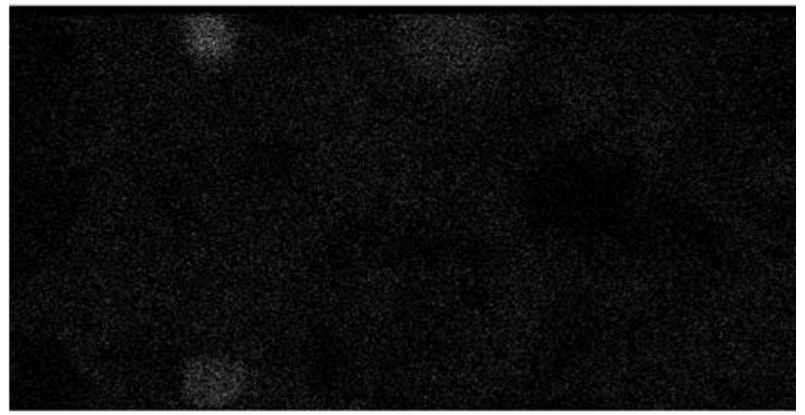

Ca Ka1

(d)

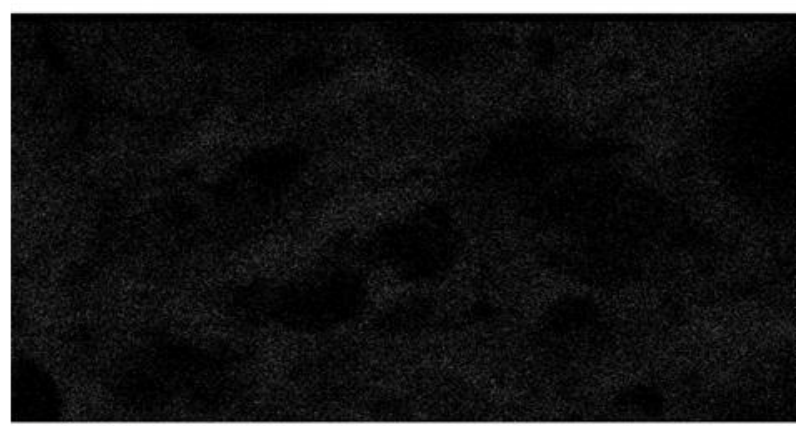

Na Ka1_2

(f)

Fig. 14 SEM image and element mapping of geopolymer using Martin Lake fly ash: (a) SEM image; (b) Al mapping; (c) Si mapping; (d) Calcium mapping; (e) O mapping; (f) Na mapping. 


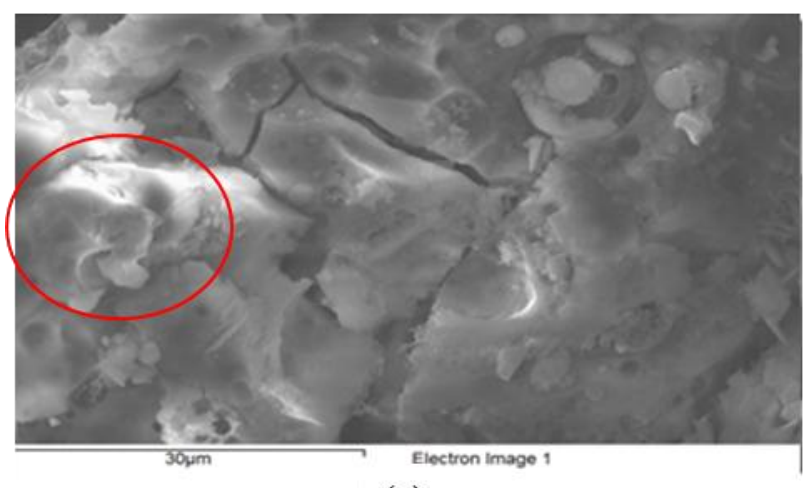

(a)

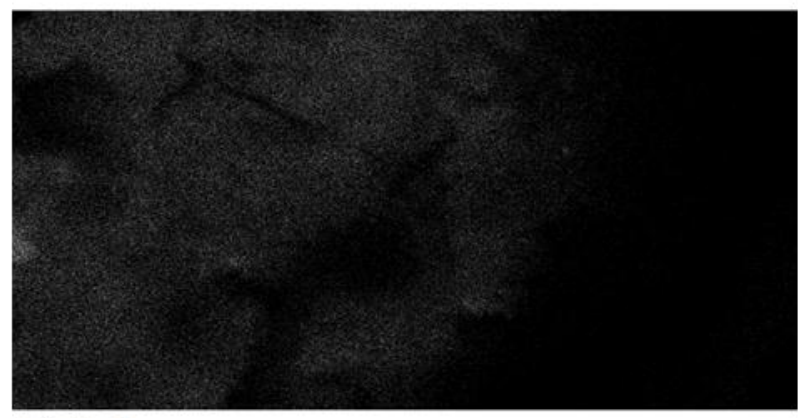

Si Ka1

(c)

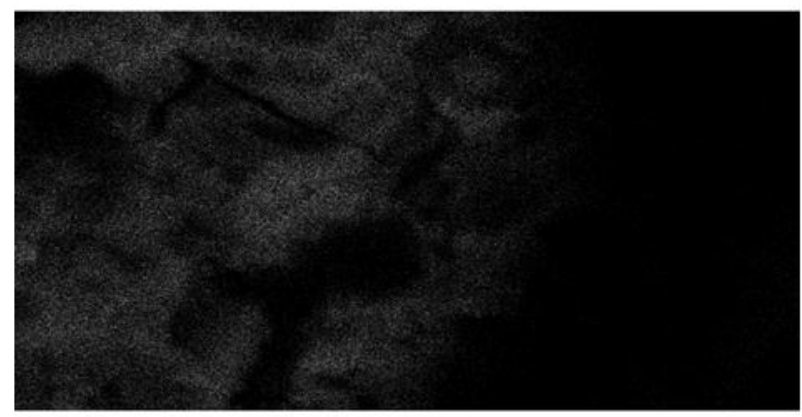

O Ka1

(e)

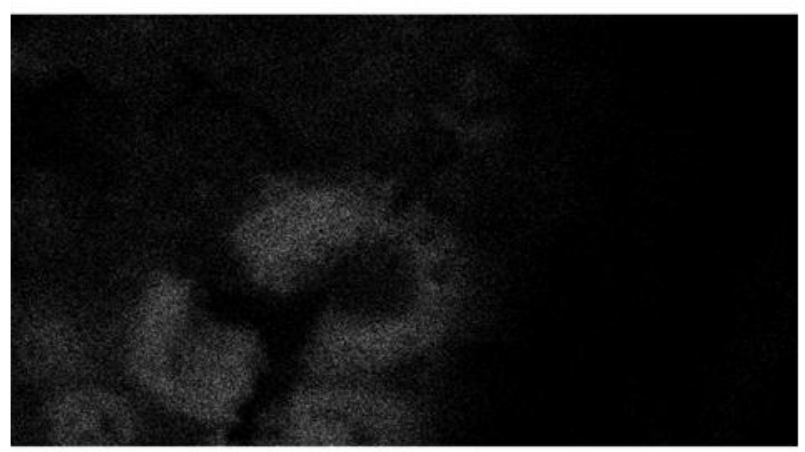

(b)

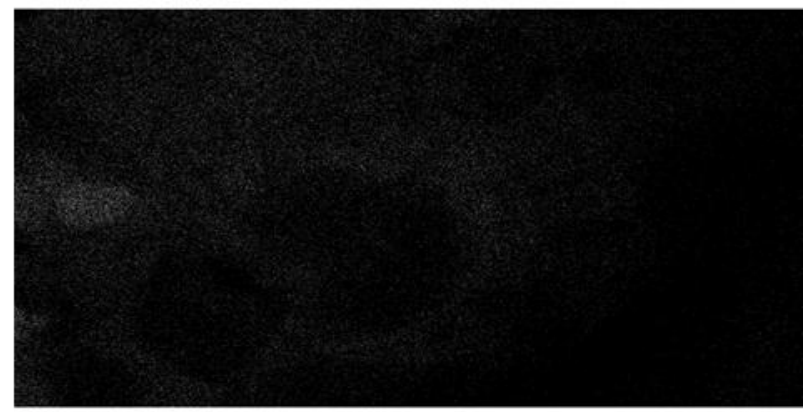

Ca Ka1

(d)

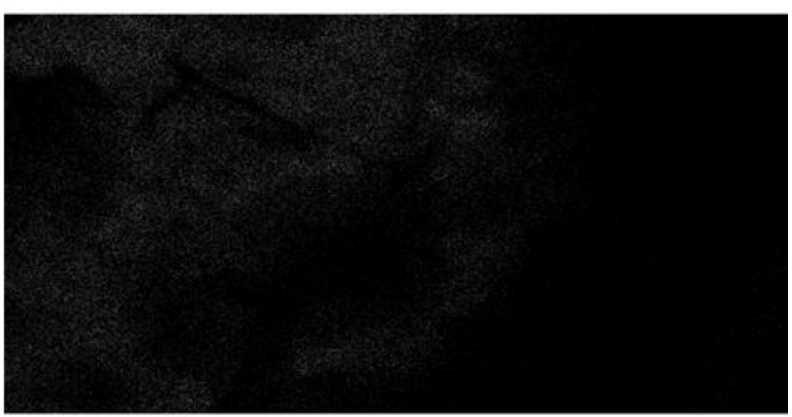

Na Ka1_2

(f)

Fig. 15. SEM image and element mapping of geopolymer using Miller fly ash: (a) SEM image; (b) Al mapping; (c) Si mapping; (d) Calcium mapping; (e) O mapping; (f) Na mapping.

\subsection{Electrical Properties Evolution with the Curing of Geopolymers}

The evolution of the electrical impedance with curing time for geopolymers based on Gaston fly ash is shown Fig. 16. It can be seen that the magnitude of the electrical impedance of geopolymer increases monstrously with curing time within the range of $100 \mathrm{~Hz}-1 \mathrm{MHz}$. This suggests that magnitude of the electrical impedance of the geopolymer within this frequency 
range can be used to monitor the degree of geopolymerization of fly ashes. Therefore, electric resistance was measured at a fixed frequency $(10 \mathrm{KHz})$ to examine the geopolymerization processes of four geopolymers, as shown in Fig. 17.

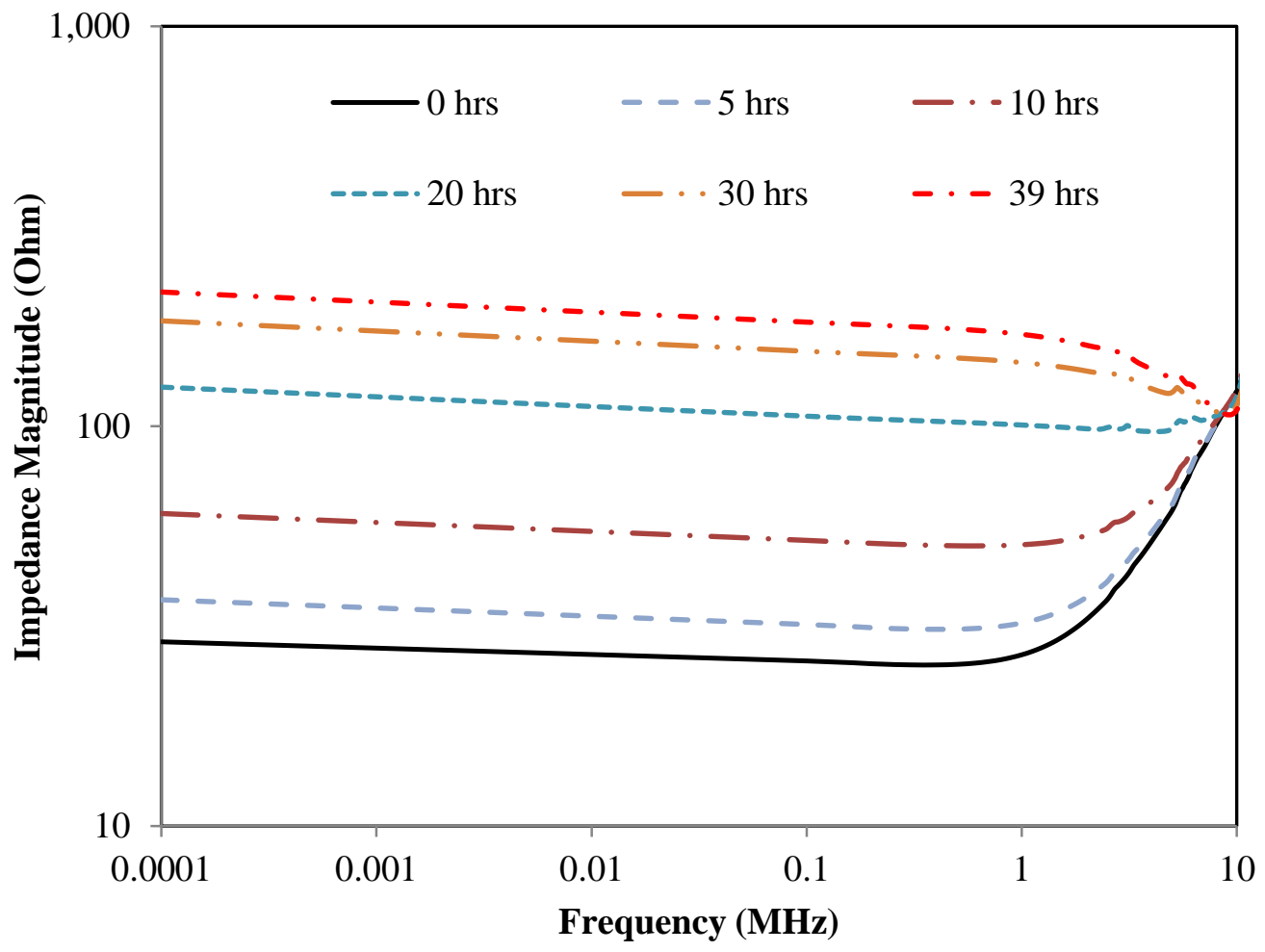

Fig. 16 Evolution of the impedance magnitude with curing time

Three duplicated specimens were tested for each geopolymer shown in Fig. 17. It can be seen that the electrical resistances of these fresh geopolymers remain almost unchanged in the first two hours of the delay time, suggesting that no or little reaction between the fly ash and alkaline activator occurred in this period. This stage is clearly the induction period of the geopolymerization. The fresh geopolymers made from Miller and Martin Lake fly ash have significantly lower electric resistance than those two made from low calcium fly ash from Gaston and Orlando. This is caused by the temperature rise induced by the reaction between $\mathrm{CaO}$ and water. High content of $\mathrm{CaO}$ in fly ash can cause higher temperature rise in the fresh geopolymer, 
which accelerate the movement of ions in the fresh geopolymer, leading to lower electrical resistance in fresh geopolymer made from Miller and Martin Lake fly ashes.

After the samples were cured in the oven, their temperatures rose quickly from the ambient temperature to $75^{\circ} \mathrm{C}$. As a result, the resistance drops sharply to a low level, as shown in Fig. 17. After the temperatures of the specimens were stable, the resistances of the geopolymer specimens would be mainly controlled by three factors: 1) continuous release of ions from fly ashes which causes resistance to decrease, 2) consolidation of the geopolymerization products which causes the resistance to increase, and 3) loss of water in the specimens which causes the resistance to increase. The driving force for the actual change of the resistance is the combination of these three factors. For all the geopolymer specimens examined in this study, their electrical resistances increase again with the curing time after $40 \mathrm{~min}$. in the oven. Three stages can be identified on the evolution of electrical resistance with curing time of geopolymer made of Miller fly ash: an initial fast increasing stage, a flat/slight increasing stage and a final increasing stage. The first fast increasing stage should be dominated by the consolidation of the geopolyerization products, as pointed by various researches $[11,12]$. The final increasing stage should be dominated by the loss of moisture, while the flat/slight increasing stage in the middle should be a combination of all these three factors. Similar features can be found on other three geopolymers.

Figure 17 shows that fast increasing stage of the all geopolymers lasts about 24 hours, suggesting that most geopolymerization was finished within this period. Due to the high reaction rate of $\mathrm{CaO}$, the resistance of the geopolymer made of fly ash with higher $\mathrm{CaO}$ content increases faster, as shown in Fig.16. Geopolymer made of high calcium fly ash from Miller has a much higher electric resistance. This may be caused by its much higher calcium 
content which not only accelerates the reaction rate, but also produces some $\mathrm{C}-\mathrm{S}-\mathrm{H}$ to densify the produced geopolymer at the early age of the geopolymer.

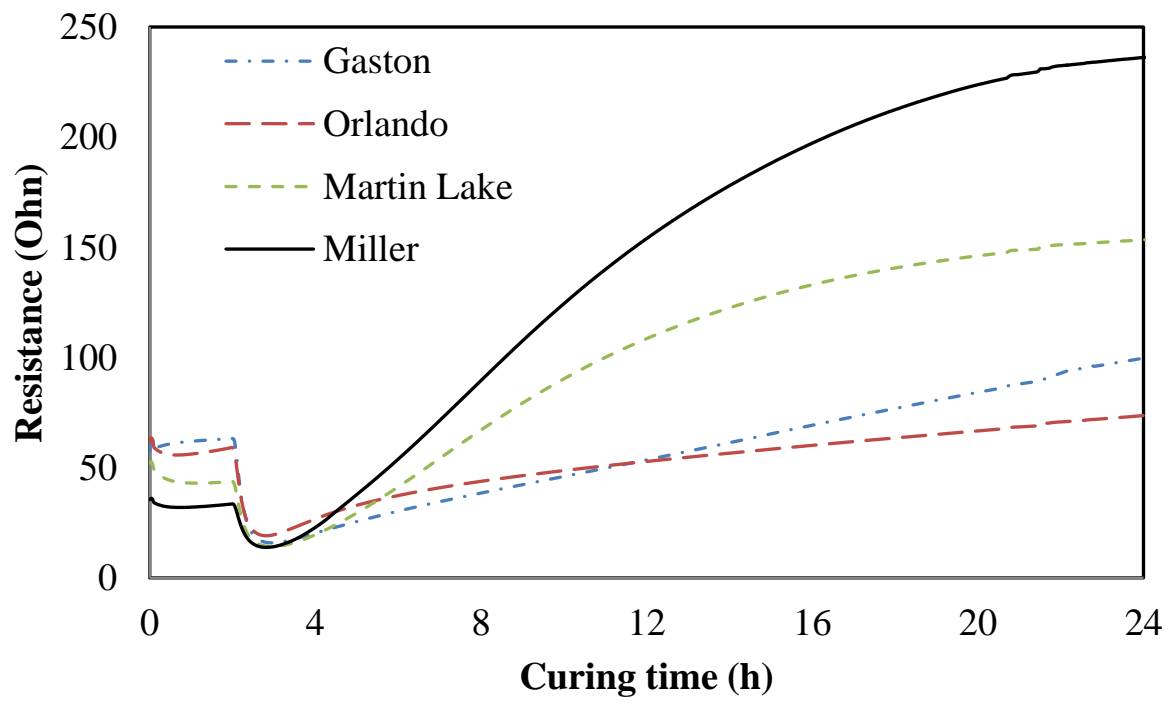

Fig. 17 Evolution of the electrical resistance with curing time

\subsection{Electrical Impedance Evolution with the Age of Geopolymers}

Electrical impedances were measured for four geopolymers over one year to examine the long-term evolution of the electrical properties of geopolymer. In this test, geopolymer specimens were cast and cured in oven at $75^{\circ} \mathrm{C}$ for 24 hours, and then stored in the laboratory environment. Figure 18 shows the Nyquist plots of the geopolymer specimens made of Martin Lake fly ash. Figure 18(a) shows the Nyquist plots of this geopolymer at the age of 5, 8, and 17 days. Two arcs can be identified in these plots based on which the bulk resistance can be determined. The diameter of the high-frequency loop increases with the age, implying that the bulk electrical resistance of this material increases with age. In Fig. 18(b), the Nyquist plots at age of 51, 108, and 384 days are presented. Because the frequency used in this test is too high, only the high-frequency arcs are captured in this figure. The diameter of the high-frequency arc continues increasing with time over one year. 
At the end of the testing, the sizes of the high-frequency arc increase by two orders of magnitudes. Although bulk resistance cannot be read from this figure, it can be qualitatively estimated because it is in proportion to the diameter of the high-frequency arc of the geopolymer. A larger diameter of the high-frequency arc implies a higher bulk resistance. Figure 18(b) shows that the bulk electrical resistance of this geopolymer increases with age over the whole testing period. At the end of the testing, its bulk resistance is in the order of $10^{5} \mathrm{ohm}$, which is in the same range as given by Davidovits [13].

Figure 19 compares the Nyquist plots of the electrical impedance spectra of four geopolymers at different ages. At the age of 8 days, the geopolymer made of fly ash from Miller has the highest bulk resistance, which is in agreement with the electrical resistant measurement shown in Fig. 17. At the age of 108 days, the diameters of the high-frequency arcs of the geopolymer made of fly ashes from Gaston and Orlando are much larger than those of the other two, as shown in Fig. 19(b). The diameters of the high-frequency arcs of all geopolymer specimens continue increasing after 108 days. At the age of 384 days, the diameters of all the arcs are almost doubled for geopolymer made of fly ashes from Gaston and Orlando, as shown in Fig. 19(c). The diameters of the high-frequency arcs of the geoplymers made of fly ashes from Martin Lake and Miller increase almost four times during this period. It is interesting to see that the diameters of the high-frequency arcs are affected by the content of $\mathrm{CaO}$ in the fly ash. The higher the content of $\mathrm{CaO}$ in the fly ash, the smaller the diameter of the high-frequency arc of the Nyquist plot of the electrical impedance. This is different from the early age observation shown in Fig. 17. At the early age, the high reaction rate of the $\mathrm{CaO}$ plays a more important role in the resistance development of the geopolymer. Therefore, the geopolymer with high $\mathrm{CaO}$ content has a 
higher resistance at the early age. However, at the late age, the fast reaction rate of the $\mathrm{CaO}$ diminishes. Because that $\mathrm{Ca}^{2+}$ ions were not integrated into the geopolymer chains, Geopolymer made of fly ash with higher calcium content may contain more free $\mathrm{Ca}^{2+}$ ions and therefore have higher conductivity, as indicated by the smaller diameter of the highfrequency arc. In addition, the dissolution degrees of fly ashes from Gaston and Orlando are higher than that of the fly ashes from Martin Lake and Miller. More reaction can be completed in the geopolymers based on these two fly ashes. As a result, more free $\mathrm{Na}^{+}$ions and other ions released from the fly ash can be consumed, and more reaction products can be generated to reduce the porosity of the geopolyers. Consequently, these two geopolymers have higher bulk electrical resistance.

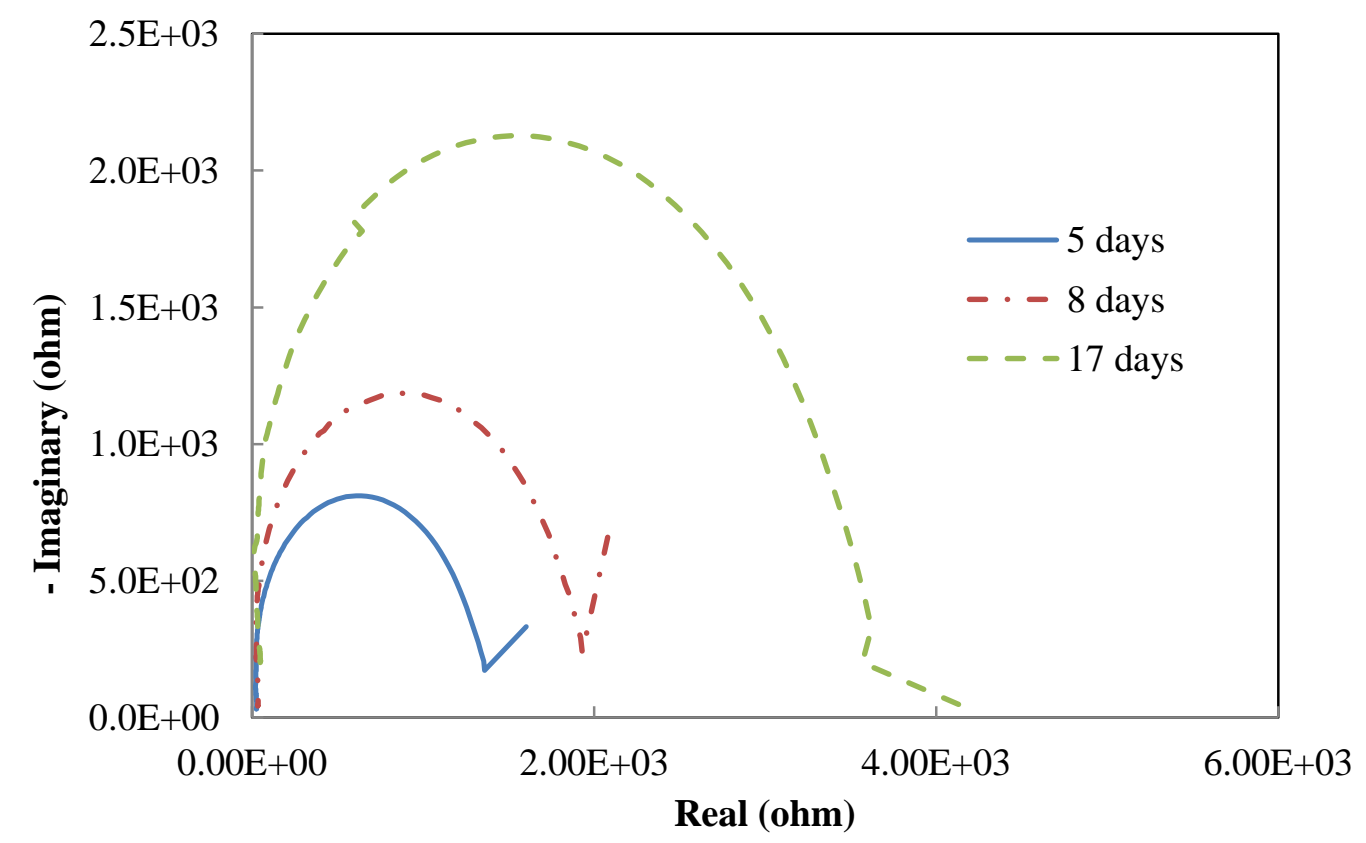

(a) 


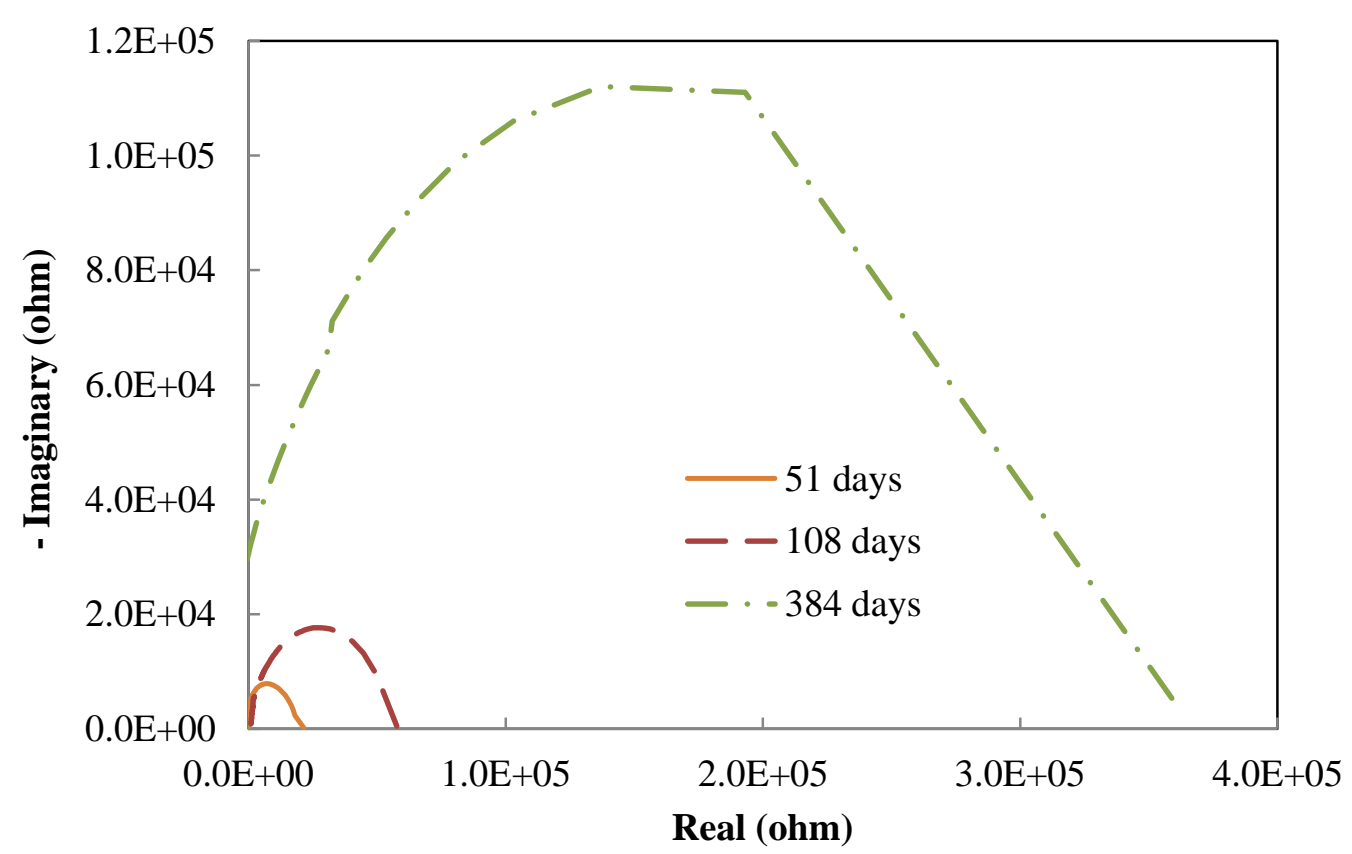

(b)

Fig. 18. Evolution of Nyquist spectra of the geopolymer specimen using Martin Lake fly ash.

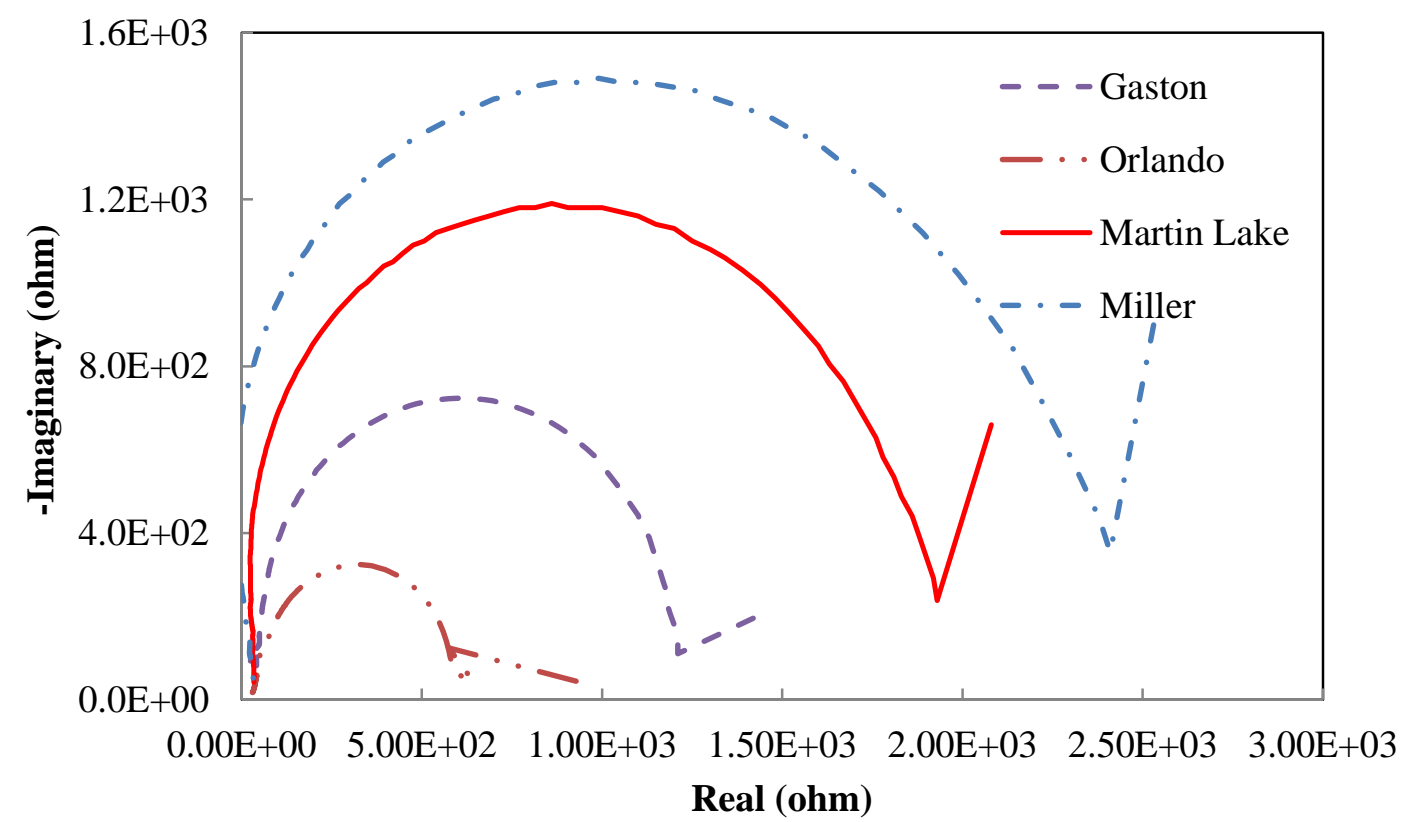

(a) 


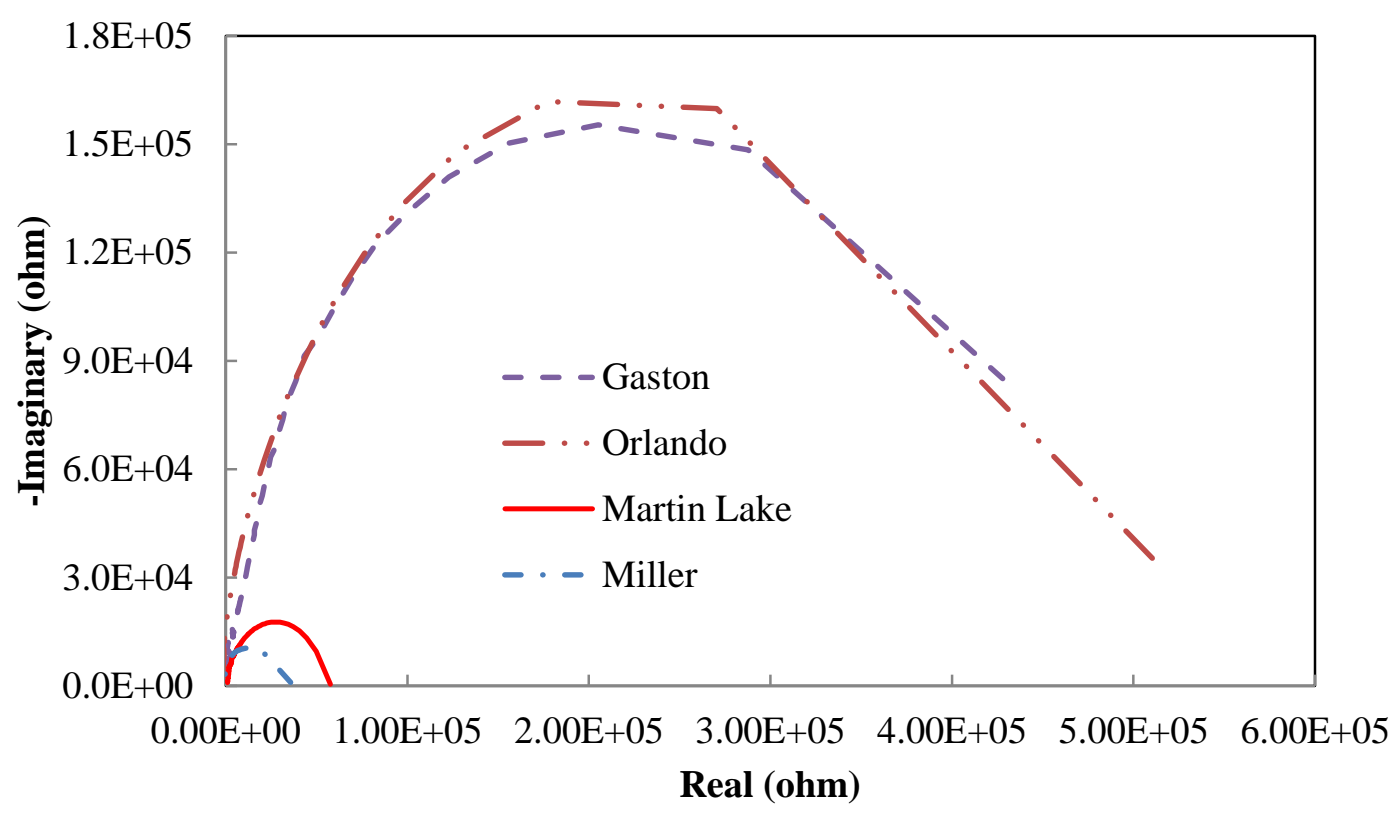

(b)

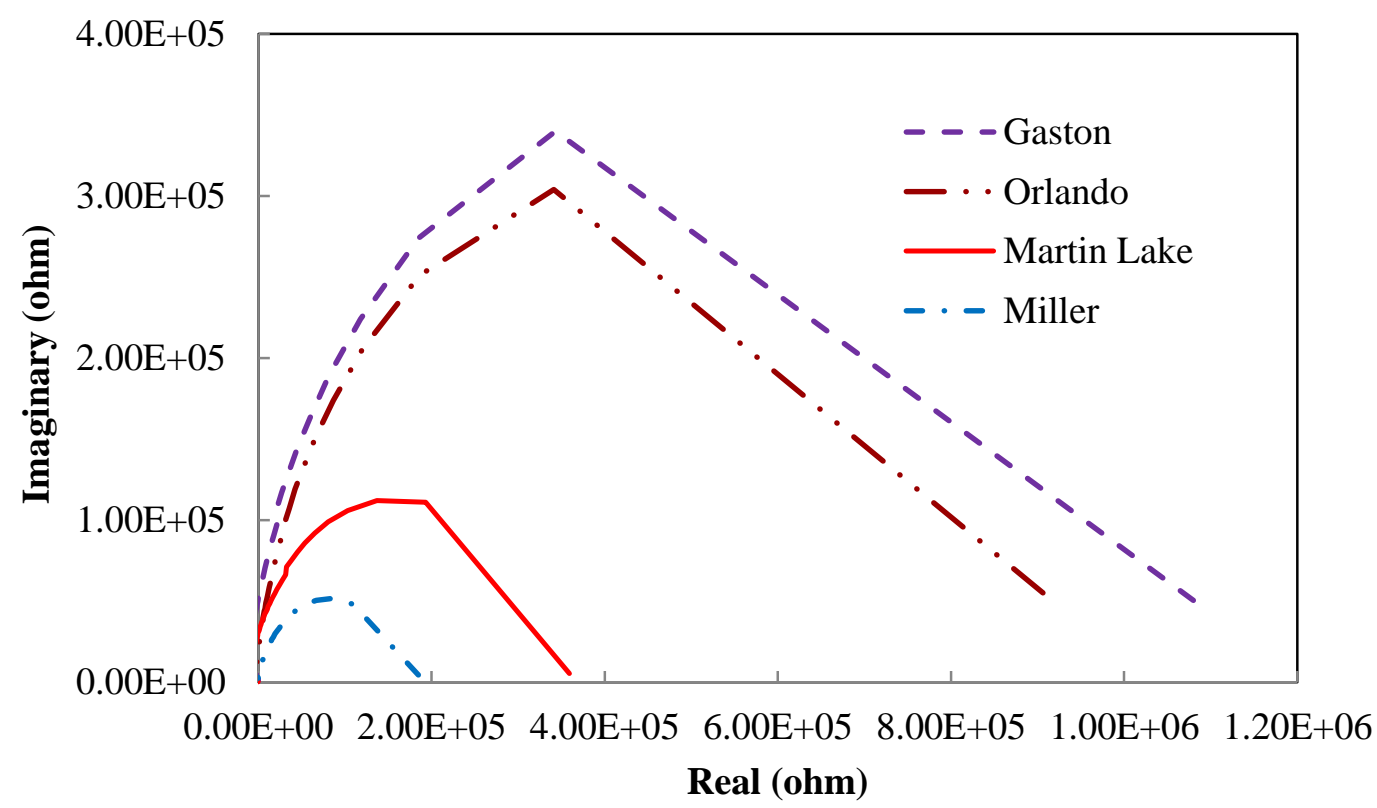

(c)

Fig. 19 Comparisons of Nyquist spectra of geopolymer made from four different fly ashes: (a) 8 days; (b) 108 days; (c) 384 days.

Figures 18 and 19 suggest that the electrical properties of geopolymers vary with age over one year. Two possible reasons are responsible for this evolution of the electrical properties: 1) 
unfinished geopolymerization in the specimens, and 2) loss of water in the testing specimens. Similar to the hydration in Portland cement, the geopolymerization of fly ash based geopolymer can take a very long period because the slow diffusion of reactive ions from the fly ash after fast reaction period at the early age shown in Fig. 17. The slow geopolymerization process can consume free ions and reduce porosity in the geopolymer specimens, leading to higher bulk resistance of the specimen. Water in the geopolymer will provide transport tool for free ions. Loss of water can therefore increase the bulk resistance of the specimen too. Since the specimens were stored in the laboratory environment, it is very likely that they lost some of their water to reach balance with the environment. Two tests were carried out to determine which reason is responsible for the change of electrical properties of the specimens observed in this study. In test I, the masses of geopolymer specimens were measured over the whole testing period to monitor the loss of moisture in the specimen. In test II, the strength of the geopoymer specimen at different age was measured to determine whether geopolymerization is undergoing or finished over the testing period.

The result of test I is shown in Fig.20. It can be seen that the masses of all specimens reduce with age, suggesting that they all lost water during the testing period. During the initial 17 days, water evaporation from these specimens was very fast. After that, water loss was much slower. The mass loss of the geopolymer made of Orlando fly ash is almost negligible after the age of 51 days. The mass of the geopolymer made of Gaston fly ash even increases a little bit after 51 days, suggesting it may absorb some water from the environment. If water content is the major reason responsible for the electrical properties evolution of the geopolymers, the diameters of the high-frequency arcs of these two geopolymers should be the same or even smaller at the age of 384 days in comparison with that of the age of 108 days. However, experimental result (Figs. 
19(b) and 19(c)) is on the opposite side. Therefore, unfinished geopolymerization should be the major reason for the increase of the diameters of the high-frequency arcs of these two geopolymers after age of 108 days. The geopolymer specimens made of the fly ashes from Miller and Martin Lake continue losing moisture slowly from the age of 51 days to 383 days, which contributed to the increase of the diameters of the high-frequency arcs of these two geopolymers.

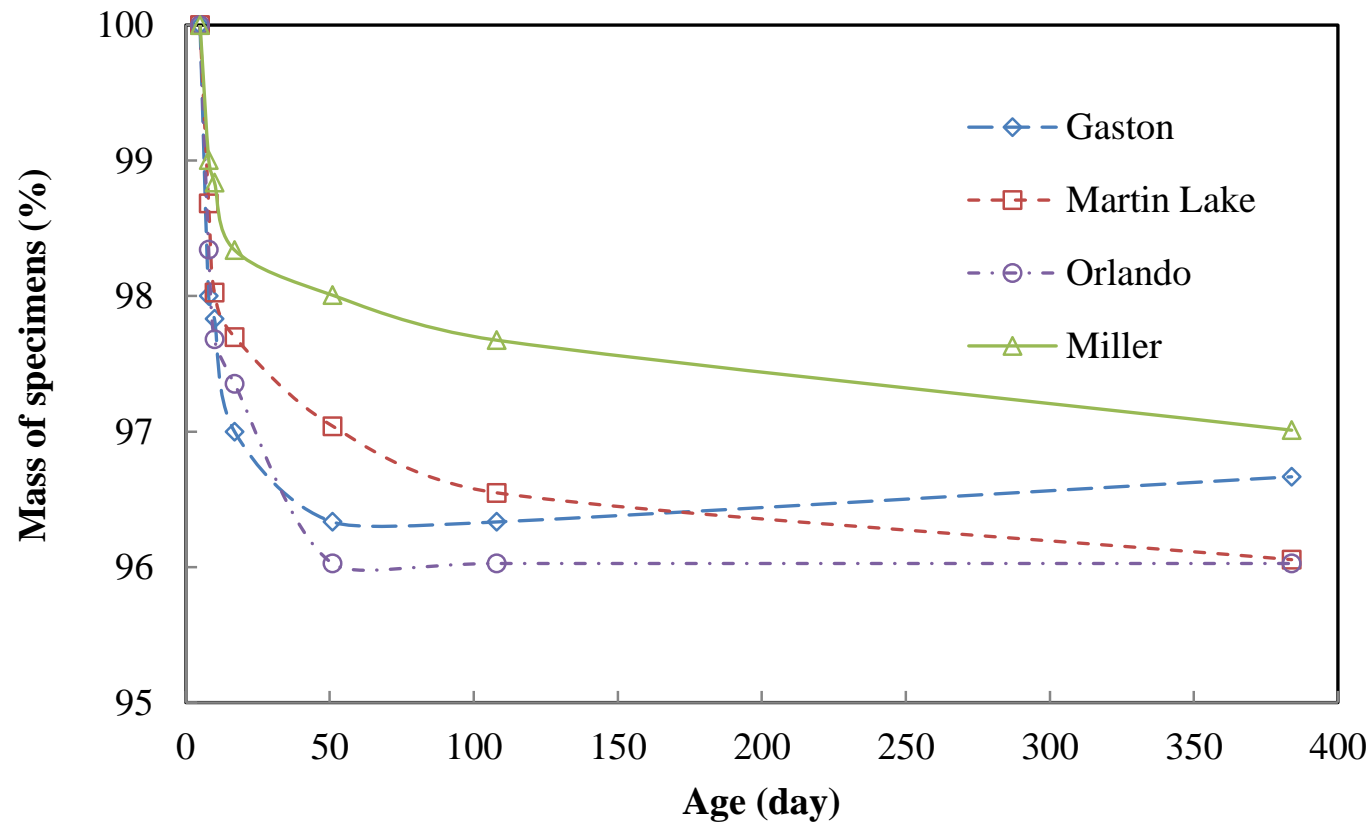

Fig. 20 Moisture loss of geopolymer specimens with age

The compressive strength of the geopolymer made of Gaston fly ash was measured at different ages over 84 days. The result is shown in Fig. 21. It can be seen that the compressive strength of this geopolymer increases with age in the testing period, suggesting that geopolymerization was ongoing over the whole period. This is similar to the hydration of the OPC, which can take over many years. In fly ash geopolymer specimens, geopolymerization can occur as long as aluminosilicate sources and alkaline activator are present. With new reaction products covering the fly ash particles, it becomes more difficult for the amorphous materials in the fly ash to diffuse through the reaction products and 
participate in the geopolymerization process. Although Fig. 21 only examines the normalized compressive strength (by the compressive strength at day 1) up to 84 days, the geopolymerization of the fly ash didn't stop after that as suggested by Figs.20 and 18 .

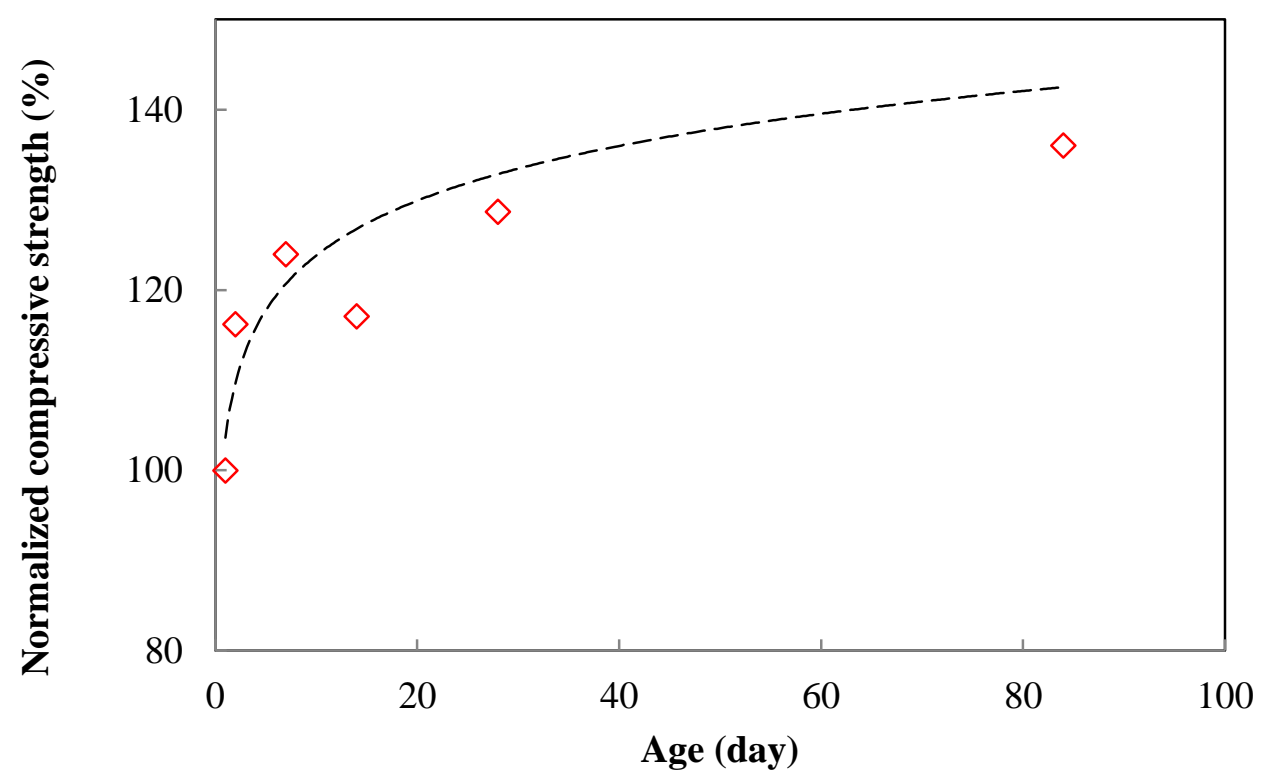

Fig. 21 Compressive strength of the geopolymer made from Gaston fly ash varies with age

\section{Conclusions}

In this study, fly ashes from four different sources were used to synthesize Geopolymer mortars. Comprehensive experimental programs have been carried out to characterize both the mechanical and electrical properties of these geopolymers. Mechanical testing shows that similar chemical composition in the source materials doesn't produce similar compressive strengths of the produced geopolymers, and that high content of calcium doesn't always lead to high compressive strength because of the reactivity of the fly ash. Electrical characterization reveals that both the magnitude of the electrical impedance and the electrical resistance of the geopolymers at early age measured increase with the curing time, suggesting that electrical resistance can be used to monitor the process of 
geopolymerization. Electrical measurement also suggests that at the early age, the electric resistance of the geopolymers is mainly determined by the reaction rate. At the late age, this electric resistance is mainly controlled by the chemical composition. Bulk electric resistances or the diameters of the high frequency arcs of all geopolymers increase with age during the one-year testing period, suggesting that the polymerization is a very long process.

\section{Acknowledgements}

This study was supported by the National Science Foundation CMMI - 1000580. Any Opinions, findings and conclusions or recommendations expressed in this material are those of the author(s) and do not necessarily reflect those of the National Science Foundation.

\section{References}

[1].McCarter, W. J., and Brousseau, R., 1990. "The A.C. Response of Hardened Cement Paste." Cement and Concrete Research 20 (6): 891-900.

[2].Tamás, F. D., Farkas, E., Vörös, M., and Roy, D.M., 1987. “Low-Frequency Electrical Conductivity of Cement, Clinker and Clinker Mineral Pastes." Cement and Concrete Research 17 (2): 340-48.

[3].Saad, M.M., 1999. "Effect of Temperature on Electrical Conductivity of Blended Cement Pastes." Cement and Concrete Research 29 (4): 603-6.

[4].Tamás, F. D., 1982. "Electrical Conductivity of Cement Pastes.” Cement and Concrete Research 12 (1): 115-20.

[5].Schwarz, N., DuBois, M., and Neithalath, N., 2007. "Electrical Conductivity Based Characterization of Plain and Coarse Glass Powder Modified Cement Pastes." Cement and Concrete Composites 29 (9): 656-66. 
[6].McCarter, W. J, Chrisp, T. M., Starrs, G., and Blewett, J., 2003. “Characterization and Monitoring of Cement-Based Systems Using Intrinsic Electrical Property Measurements." Cement and Concrete Research 33 (2): 197-206.

[7].Cui, X.M., Zheng, G.J., Han, Y.C., Su, F., and Zhou, J., 2008. “A Study on Electrical Conductivity of Chemosynthetic Al2O3-2SiO2 Geoploymer Materials." Journal of Power Sources 184 (2): 652-56.

[8].Hanjitsuwan, S., Chindaprasirt, P., and Pimraksa, K., 2011. "Electrical Conductivity and Dielectric Property of Fly Ash Geopolymer Pastes." International Journal of Minerals, Metallurgy, and Materials 18 (1): 94-99.

[9].Rickard, W.D.A., Williams, R.P., Temuujin, J., van Riessen, A., 2011. "Assessing the Suitability of Three Australian Fly Ashes as An Aluminosilicate Source for Geopolymers in High Temperature Applications.” Mater. Sci. Eng. A, 528: 3390-3397.

[10]. Chindaprasirt, P., Chareerat, T., and Sirivivatnanon, V., 2007. "Workability and Strength of Coarse High Calcium Fly Ash Geopolymer." Cement and Concrete Composites 29 (3): $224-29$.

[11]. Van Jaarsveld, J. G. S., Van Deventer, J. S. J., and Lorenzen, L., 1997. “The Potential Use of Geopolymeric Materials to Immobilise Toxic Metals: Part I. Theory and Applications." Minerals Engineering 10 (7): 659-69. doi:10.1016/S0892-6875(97)00046-0.

[12]. Hardjito, D., Wallah, S. E., Sumajouw, D., and Rangan, B. V., 2004. "Factors Influencing the Compressive Strength of Fly Ash-Based Geopolymer Concrete." Civil Engineering Dimension 6 (2).

[13]. Davidovits, J., 2008. Geopolymer Chemistry and Applications. Geopolymer Institute. 
[14]. Van Jaarsveld, J.G.S., van Deventer, J.S.J., and Lukey, G.C., 2002. "The Effect of Composition and Temperature on the Properties of Fly Ash- and Kaolinite-Based Geopolymers." Chemical Engineering Journal 89 (1-3): 63-73. 